\title{
Tabularia
}

\section{La « féodalité » et la seigneurie dans la Calabre méridionale normande : une institution politique pour bâtir la paix?}

"Feudality" and Lordship in Southern Norman Calabria: A Political Institution to Build Peace?

La "feudalità" e la signoria nella Calabria meridionale normanna: una istituzione politica per costruire la pace?

Lehnswesen und Lehnsherrschaft in der normannischen Grafschaft Kalabrien: eine politische Institution zur Friedensstiftung?

\section{Riccardo Berardi}

\section{(2) OpenEdition}

Journals

Édition électronique

URL : http://journals.openedition.org/tabularia/4922

DOI : $10.4000 /$ tabularia.4922

ISSN : 1630-7364

Éditeur :

CRAHAM - Centre Michel de Boüard, Presses universitaires de Caen

Référence électronique

Riccardo Berardi, «La « féodalité » et la seigneurie dans la Calabre méridionale normande : une institution politique pour bâtir la paix? », Tabularia [En ligne], Mémoires normandes d'Italie et d'Orient, mis en ligne le 18 décembre 2020, consulté le 20 décembre 2020. URL : http:// journals.openedition.org/tabularia/4922 ; DOI : https://doi.org/10.4000/tabularia.4922

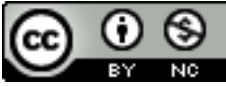

la revue Tabularia est mise à disposition selon les termes de la Licence Creative Commons Attribution - Pas d'Utilisation Commerciale 4.0 International. 

La «féodalité» et la seigneurie dans la Calabre méridionale normande: une institution politique pour bâtir la paix?

"Feudality" and Lordship

in Southern Norman Calabria:

A Political Institution to Build Peace?

La "feudalità" e la signoria

nella Calabria meridionale normanna:

una istituzione politica per costruire la pace?

Lehnswesen und Lehnsherrschaft

in der normannischen Grafschaft Kalabrien:

eine politische Institution zur Friedensstiftung?

Riccardo BERARDI

Università della Calabria,

Bourse postdoc «Robert de Sorbon» au Lamop (Université Paris I),

membre associé du Craham et de l'UMR 8167 «Orient et Méditerranée »

rickberardi@libero.it

Résumé:

L'objet de cette étude est d'examiner comment la «féodalité» et la seigneurie dans la Calabre méridionale normande ont aidé à reconstruire l'état de paix et quelle est l'originalité de la transition entre l'état de guerre et la nouvelle construction politique des Normands. Robert Guiscard, avec son frère le Grand Comte Roger, a conquis la Calabre: le centre et le nord ont été incorporés au duché de Pouille gouverné par Guiscard, tandis que le sud a été joint à la Sicile (qui n’a été définitivement conquise que dans les dernières années du XI ${ }^{e}$ siècle) et donné à Roger I ${ }^{\mathrm{er}}$. Dans le sud de la Calabre, la situation était étroitement contrôlée par le Grand Comte, puissant aristocrate qui a bâti les fondations du futur «État normand», fondé par son fils Roger II.

Mots-clés: Calabre, féodalité, seigneurie, conquête normande, royaume de Sicile, Empire byzantin

Abstract:

The objective of this study is to examine whether "feudalism" and lordship in southern Norman Calabria was important to reinstate peace and what were its original characters in the transition from the state of war and the new political construction of the Normans. Robert Guiscard with his brother the Great Count Roger, conquered Calabria: the centre and the north were incorporated in the duchy of Puglia and governed by Guiscard, whereas the

Tabularia "Études», "Mémoires normandes d'Italie et d'Orient», 2020, p. 1-52, 18 décembre 2020 URL: http://journals.openedition.org/tabularia/4922 | DOI: 10.4000/tabularia.4922 
south was united to Sicily (as definitively conquered in the last years of the 11th century) and donated to Roger I. Southern Calabria, was under the grip of the Grand Count who built the "Norman State" which would be the model of Norman Monarchy as later accomplished by his son Roger II.

Keywords: Calabria, feudalism, Lordship, Norman Conquest, Kingdom of Sicily, Byzantine Empire

Riassunto:

Gli obiettivi di questo studio sono di esaminare se la "feudalità" e la signoria nella Calabria meridionale normanna abbiano contribuito a ricostruire lo Stato di pace e scoprire quale sia stata l'originalità del passaggio dallo Stato di guerra alla nuova costruzione politica dei Normanni in questa "subregione". Roberto il Guiscardo, con suo fratello Ruggero il Gran Conte, conquistò la Calabria: il centro-nord fu incorporato nel ducato di Puglia, governato dal primo; il sud, unito alla contea di Sicilia (isola che fu definitivamente conquistata negli ultimi anni dell'XI secolo), venne concesso invece a Ruggero il Gran Conte. Verrà approfondita la storia della Calabria meridionale, la cui distribuzione del potere rimase strettamente controllata da Ruggero I, potente aristocratico che costrui le basi del futuro "Stato Normanno", fondato da suo figlio Ruggero II.

Parole chiave: Calabria, feudalesimo, signoria, conquista normanna, Regno di Sicilia, Impero bizantino

Abstrakt:

Gegenstand dieser Untersuchung ist die friedensstiftende Wirkung des Lehnswesens und der Lehnsherrschaft im südlichen normannischen Kalabrien und die Frage nach der Ursprünglichkeit dieses Umbaus zwischen Kriegszustand und Aufbau einer neuen politischen Entität durch die Normannen. Robert Guiscard hatte zusammen mit seinem Bruder, dem Grafen Roger, Kalabrien erobert: Das Zentrum und der Norden wurden in das von Guiscard regierte Herzogtum Apulien eingebunden, während der Süden mit Sizilien (das endgültig in den letzten Jahren des 11. Jahrhunderts erobert wurde) vereint und Roger übergeben wurde. Im Süden Kalabriens, war die Situation unter der straffen Kontrolle des magnus comes, ein starker Herrscher, der für den zukünftigen „normannischen Staat“, den sein Sohn Roger II. formen sollte, die Grundlagen schuf.

Schlagworte: Kalabrien, Lehnswesen, Lehnsherrschaft, normannische Eroberung, Königreich Sizilien, Byzantinisches Reich

\section{Introduction}

Le grand débat lié au "féodalisme» et aux pouvoirs seigneuriaux a animé l'historiographie médiévale du $\mathrm{XX}^{\mathrm{e}}$ siècle attirant des chercheurs pour tenter de comprendre la dynamique qui, dans les différents contextes européens, de caractère régional, a caractérisé l'évolution des systèmes politiques, économiques et sociaux, entre le haut et le bas Moyen Âge. Il s'agit d'un thème qui a joué un rôle central dans le panorama de la recherche sur l'Italie méridionale ces dernières années, comme en témoignent les nombreuses contributions sur le sujet et la récente et brillante monographie de Sandro Carocci. Que 
nous apprend la Calabre méridionale comtale, puis monarchique, à propos de la récente critique radicale constituée par le refus d'attribuer des caractères «féodaux» aux possessions et aux domaines de l'aristocratie (et de l'Église) encore aux $\mathrm{XI}^{\mathrm{e}}-\mathrm{XII}^{\mathrm{e}}$ siècles?

Les structures «féodales» et seigneuriales sont très originales dans la Calabre des $\mathrm{XI}^{\mathrm{e}}-\mathrm{XII}^{\mathrm{e}}$ siècles, par rapport au reste de l'Occident puisque la seigneurie banale et la «féodalité» sont inconnues en Calabre à l'arrivée des Normands; ce sont donc des "importations», même si nous devons considérer - comme nous le verrons - que ce système s'intègre parfaitement à la structure foncière préexistante. Comment les comtes et ducs de la maison de Hauteville ont-ils utilisé à la fois les spécificités de la Calabre byzantine et les opportunités de ce terrain «vierge» de toute structure seigneuriale et banale, pour faire des seigneuries qu'ils ont concédées à leurs compagnons de conquête, des instruments de stabilisation politique, c'est-à-dire des moyens pour passer, au profit de la dynastie Hauteville, de l'état de conquête à l'état de paix?

La Calabre était fortement marquée par l'héritage de la domination byzantine, mais avec une petite distinction entre partie nord et partie sud; en effet, la partie sud de la région est la seule zone des territoires byzantins italiens qui soit restée, pratiquement sans interruption, sous domination impériale depuis la conquête de Justinien jusqu'au milieu du $\mathrm{XI}^{\mathrm{e}}$ siècle. La conquête n'a pas unifié la mosaïque «régionale»; en effet, elle a au départ aggravé la diversité, puisque la partie centre-nord a été annexée au duché de Pouille, tandis que le sud de la Calabre dans les dernières années du $\mathrm{XI}^{\mathrm{e}}$ siècle se trouvait dans le comté de Sicile. Même s'il convient de noter que le centre-nord de la Calabre possède également un fort héritage byzantin, c'est un territoire différent de celui où s'est construite la «féodalité» des autres «mondes normands"; l'imposition du modèle de la double seigneurie, foncière et banale, ne fonctionne pas dans cette région très particulière, où les droits de justice ne sont pas concédés aux seigneurs, où la seigneurie est administrative et aux ordres du comte, puis du roi, où les banalités sont rarissimes, où l'autorité publique, en bref, n'est presque jamais concédée à titre privé aux seigneurs, dont le rôle se limite à exercer un pouvoir foncier qui contrôle les hommes et ne lève que peu de taxes; enfin la dîme n'est pas introduite (ce que compense la concession, par le souverain, des dîmes sur les revenus publics). L'aristocratie de fonction et l'aspect fiscal et administratif jouent un rôle fondamental dans ce type de seigneurie, en particulier en ce qui concerne l'implication de l'élite locale dans le nouveau système politique; pour cette raison, ces aspects ne seront pas traités séparément. La Sicile, politiquement unie à la Calabre comtale, sera analysée grâce à quelques exemples en note, tandis que le rôle des centres urbains calabrais ne sera pas discuté - sinon indirectement - bien qu'ils restent dans l'ombre des institutions ecclésiastiques et de la société noble, et constituent toujours l'un des piliers de la société calabraise de tradition byzantine ${ }^{1}$.

1. Sur les villes calabraises voir FALKENHAUSEN, 2019. Je remercie Kristjan Toomaspoeg (Université du Salento) de m'avoir proposé d'inclure cette période (sur l'importance des villes pour la construction de la paix sociale) dans mon article. 
Pour décrire ce processus et présenter la situation de la Calabre byzantine, on examinera comment les Normands, après la conquête territoriale, ont infiltré les sphères du pouvoir byzantin en utilisant leurs structures occidentales, transformant la seigneurie en une réalité politique et administrative déjà bien contrôlée à l'époque pré-monarchique. Cette évolution était fondamentale pour passer d'un état de guerre à une conquête territoriale, puis enfin à un état de paix qui sera consolidé - avec un retard marqué - dans d'autres régions avec la construction et la consolidation de la monarchie. La Calabre méridionale est également particulière, par rapport à toutes les autres régions du royaume, car le contrôle strict de Roger $\mathrm{I}^{\mathrm{er}}$, puis des souverains, d'abord sur l'installation des nobles, puis sur leur comportement, a transformé les aristocraties en un seul instrument pour la paix du royaume.

\section{La Calabre byzantine}

Lorsque les Normands sont arrivés en Italie du Sud, la Calabre était une région essentiellement grecque et byzantine ${ }^{2}$. Bien que les sources soient peu nombreuses, nous pouvons reconstituer à grands traits le tissu de la propriété foncière ainsi que la structure socio-administrative à l'époque pré-normande, qui sont d'une importance fondamentale pour comprendre les mutations et les continuités de la société normande.

La zone comprenait alors des propriétés foncières de toutes dimensions.

\section{Propriété ecclésiastique}

Les propriétés de grande taille appartenaient surtout aux monastères italo-grecs importants, ainsi qu'à des institutions ecclésiastiques (évêchés) et à quelques "grands» laïcs. On sait que la nouvelle cathédrale d'Oppido (actuellement Oppido Mamertina-Palmi) possédait un ensemble foncier qu'on peut qualifier de «moyen-grand $»^{3}$, tandis que la métropole de Reggio (actuellement Reggio Calabria) détenait un ensemble foncier imposant, décrit dans un document d'époque byzantine (vers le milieu du XI ${ }^{\mathrm{e}}$ siècle), le Brébion ( $\beta \rho \varepsilon \dot{\beta} ı$ ) $)$ (inventaire des biens et des possessions de la métropole $)^{4}$.

Les informations sur la propriété de la cathédrale d'Oppido viennent de son cartulaire qui est copié au verso du rouleau du Brébion; il comprend 47 documents: quatre issus de l'administration ecclésiastique, 43 actes privés, dont 42 donations et une attestation de propriété rédigés en grec entre 1050 et 1064-1065.

2. Sur l'histoire de la Calabre byzantine voir Peters-Custot, 2009a, p. 85 sq. (je remercie Annick Peters-Custot [Université de Nantes] pour les nombreux conseils qu'elle m'a donnés pour chaque partie de cet article). Pour la toponymie calabraise citée dans cet article voir RoHLFs, 1974, sub vocibus.

3. La Thèotokos de Hagia-Agathè (Oppido) (1050-1064/1065), A. Gulllou (éd.).

4. Le brébion de la métropole byzantine de Règion (vers 1050), A. Guillou (éd.). 
La plus importante donation semble venir de la moniale Jeanne qui a offert une partie de l'héritage paternel et maternel, située dans la ville d'Oppido, à Reggio, S. Agata et dans quatre autres communautés rurales ${ }^{5}$. Nous assistons, avec ces nombreuses donations, à la constitution du domaine foncier d'un évêque grec à l'époque de la conquête normande, qui présentait des types d'exploitation différents (salines, moulins, terres de labour, etc.); il convient également de noter que presque tous les biens étaient en pleine propriété, sauf pour un cas d'emphytéose ${ }^{6}$ et certaines donations qui sont laissées aux locataires en échange d'un cens. Cependant, il faut aussi tenir compte du fait qu'en temps de guerre les propriétaires laïcs cédaient souvent leurs biens aux institutions ecclésiastiques pour les soustraire aux envahisseurs.

Le Brébion de Reggio est un document exceptionnel actuellement composé de onze feuillets. En effet, il s'agit du seul exemple conservé, pour tout l'Empire byzantin, d'un tel document pour l'histoire de la propriété foncière; il mérite donc une attention particulière. Le Brébion ainsi que deux autres documents relatifs au monastère de $\mathrm{S}$. Leonzio près de Stilo (Calabre méridionale $)^{7}$ nous montrent qu'il existait en Calabre des registres ( $\kappa \dot{\omega} \delta\llcorner\kappa \varepsilon \varsigma)$ et des structures cadastrales similaires à ceux mentionnés dans le reste de l'Empire byzantin au moins à partir $\mathrm{du} \mathrm{IX}^{\mathrm{e}}$ siècle $^{8}$. Ces registres, très importants puisque le système fiscal byzantin était basé sur l'imposition de la terre, contenaient le nom du contribuable, sa propriété foncière et la somme de la taxe correspondante; de plus, en principe, ils devaient être mis à jour assez régulièrement (tous les trente ans environ) ${ }^{9}$. En raison de l'absence de protocole et d'eschatocole dans le Brébion (avec le titre du document, la date, les noms ou les titres des responsables, à la fois impériaux et ecclésiastiques, qui ont commandé son élaboration et qui l'ont signé), nous ne connaissons malheureusement ni le titre du rouleau, selon la terminologie fiscale byzantine, ni le nom et la fonction de la personne qui l'avait élaboré, ni

5. La Thèotokos de Hagia-Agathè..., doc. 22, 26, 28-29, 32, 40, 42, 44 et 47.

6. L'emphytéose est un droit sur les biens-fonds de quelqu'un d'autre qui donne au tenancier (emphytéote) les mêmes droits que le propriétaire (constituant) aurait sur les fruits et l'utilisation du sous-sol. Le locataire a deux obligations fondamentales: celle de payer une redevance périodique (qui peut consister à la fois en une somme d'argent et un montant fixe de produits naturels) au constituant et celle d'améliorer le fonds. Les taxes et autres droits qui pèsent sur le bien sont généralement à la charge de l'emphytéote.

7. Ces deux parchemins, provenant des archives du monastère calabrais de San Bruno, ont été détruits pendant la seconde guerre mondiale, ainsi que les fonds médiévaux de l'Archivio di Stato de Naples. Toutefois, ils avaient été publiés en 1865 par Francesco Trinchera, malheureusement sans aucune description des originaux (voir Syllabus graecarum membranarum..., F. TRINCHERA [éd.], doc. 44; annexe II doc. 15, p. 555-557). Les documents ont été étudiés avec précision par Annick Peters-Custot. Voir Peters-Custot, 2008. En réalité, même dans un document de la

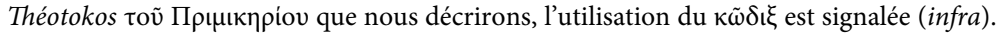

8. Voir Svoronos, 1959; Lefort, 1981; Oikonomidès, 2002, p. 982-992. Dans les territoires

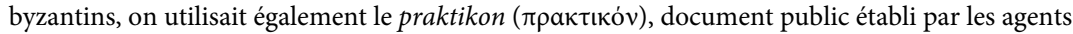
des autorités fiscales byzantines et destiné à un propriétaire (personne physique ou corps religieux) d'une importance considérable. Voir Peters-Custot, 2008, p. 538-539, qui offre quelques exemples de ce document.

9. Dölger, 1927, p. 54-57, 97-100; Oikonomidès, 1996, p. 46-66; FAlKenhausen, 2012, p. 533. 
quelle autorité en avait commandé la rédaction ${ }^{10}$. Nous ne connaissons pas la date précise de la source, mais l'éditeur (André Guillou) en situe le terminus ante quem à 1041 pour des raisons qui ne sont pas évidentes ${ }^{11}$, alors qu'Annick PetersCustot a montré qu'il était certainement antérieur à $1044^{12}$. Cela étant, au-delà de la datation, l'inventaire expose en détail les avantages que donnaient aux monastères byzantins les dispositions du droit canon. La plus grande partie de la Calabre byzantine était ainsi soumise au métropolite de Reggio: nous avons donc une image plutôt précise des possessions ecclésiastiques grandes et moyennes dans la région à la fin de la domination byzantine. La métropole, qui tirait des revenus de certaines communes et monastères ruraux, comptait par ailleurs 281 grands domaines ( $\pi \rho \circ \alpha \dot{\sigma} \tau \varepsilon\llcorner\alpha$ ); en outre, sept $\chi \omega$ pia (villages, cellules fiscales fondamentales) exonérés dépendaient de la métropole, ce qui signifie qu'elle y percevait des impôts à la place de l'État ${ }^{13}$.

\section{Propriété laïque}

Les propriétaires laïcs ${ }^{14}$ mentionnés dans le Brébion peuvent être répartis en trois catégories: les familles de l'élite italo-grecque, qui présentent au moins un exemple de propriété collective et familiale; les agents administratifs et militaires de l'Empire byzantin, parmi lesquels certains détenaient des biens-fonds de taille moyenne à grande (par exemple les кoupátopec) ${ }^{15}$; ainsi que les dignitaires impériaux (titulaires de titres honorifiques concédés par l'empereur et procurant

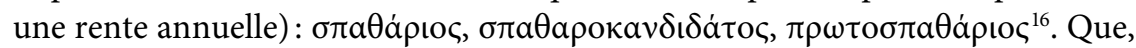
parmi les laïcs, les plus riches soient les détenteurs de fonctions publiques ou de dignités est compréhensible et normal dans le cadre byzantin: les fonctions et les dignités ont été confiées à des personnes déjà notables et, bien évidemment, la rente ou le traitement les a enrichies. Les hauts responsables byzantins pouvaient même se soustraire à la loi qui leur interdisait de posséder des biens fonciers dans la province dont ils avaient la charge. Donc même si les sources sont

10. Pour une comparaison avec d'autres documents de l'Empire byzantin voir au moins ces volumes: Actes de Lavra I. Première partie: des origines à 1204, P. Lemerle, A. Guillou, D. Papachryssanthou et N. Svoronos (éd.); Actes du Prôtaton, D. Papachryssanthou (éd.); Actes de Docheiariou, N. Oıкonomidès (éd.); Actes d'Iviron. I. Des origines au milieu du $X I^{e}$ siècle, J. Lefort, N. Oikonomidès et D. Papachryssanthou (éd.) et tous les autres volumes de la collection Archives de l'Athos.

11. Le brébion..., p. 5-8.

12. Peters-Custot, 2008, p. 540, n. 13. Pour une discussion plus détaillée sur la datation du Brébion de Reggio, voir BERARDI, 2017a, chapitre II : La peculiarità della signoria calabrese: il periodo pre-monarchico.

13. Martin, 2001, p. 499.

14. Il est évident que nous avons aussi des exemples d'ecclésiastiques qui détiennent une propriété

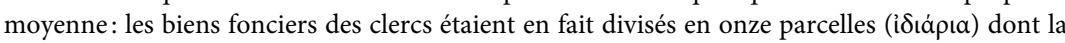
cathédrale de Reggio percevait des revenus. Par exemple le prêtre de Mouron, probablement un clerc de la cathédrale, possédait de nombreuses propriétés (19 fonds de taille moyenne), il a payé à la cathédrale pour leur possession 116 tarins. Voir Le brébion..., p. 79-80.

15. Sur les кoupáto $\varepsilon \varepsilon \varsigma$ voir CHEYNET, 2010.

16. Sur ces titres, voir MARTIN, 2010. 
parcimonieuses, l'aristocratie byzantine, présente dans la région avec des titres et des fonctions, comprenait des propriétaires fonciers moyens ou importants - comme partout ailleurs dans l'Empire ${ }^{17}$.

Pour la moyenne propriété, principalement laïque, nous disposons de deux autres exemples importants, tous les deux situés à Stilo (Calabre méridionale, vers Squillace). Le premier concerne la propriété de l'église de la Théotokos

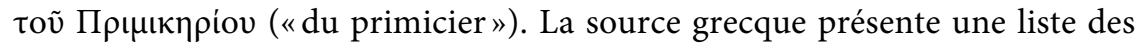
propriétés de l'église dans le village de Rousyton (Rosito) près de Stilo, établie d'après les indications d'un extrait du testament du fondateur (daté de mai 1040),

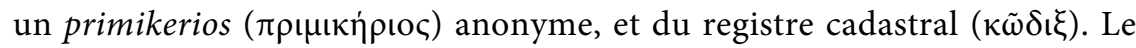
"primicier» était un dignitaire ecclésiastique: le fondateur peut donc être classé dans la catégorie des moyens propriétaires, car, malgré l'absence de legs familiaux dans le testament (mais nous ne disposons pas du testament complet, qui devait probablement être antérieur à 1040), le legs à l'église comprenait, à lui seul, des mûriers, des vignes, des oliviers et des terres arables ${ }^{18}$.

Le second document, daté de 1054, concerne une famille italo-grecque de

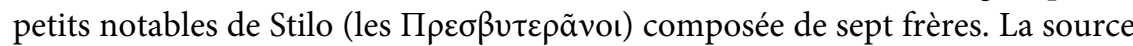
décrit les terres détenues par la famille, dispersées dans plusieurs communes rurales. Cette propriété - contrairement à la propriété ecclésiastique - est dispersée par les héritages ${ }^{19}$.

Pour résumer, le thème byzantin (c'est-à-dire la province) de Calabre abritait à la fois cette grande propriété, qui n'est pas documentée dans les régions voisines ${ }^{20}$, et qui fournit la base matérielle et territoriale à l'imposition originelle du régime seigneurial au début de l'époque "normande $»^{21}$, et une aristocratie laïque dotée de titres et de fonctions, et bien intégrée dans le cadre administratif et dans la législation civile impériale ${ }^{22}$. L'autorité sur les hommes

17. Pour une comparaison avec les possessions de l'aristocratie de l'Empire byzantin, voir CHEYNET, 1991; Patlagean, 2007, p. 107 sq.

18. Archives du Collegio Greco di Roma, Fondo abbazia di Mileto, A, II. La source, avec des commentaires, sera publiée par FALKENHAUSEN, sous presse. Je remercie Vera von Falkenhausen de m'avoir permis de lire cet article important avant sa publication. Sur le titre de primikerios voir OIKONOMIDÈs, 1972, p. 51, 125-133 et $s q$.

19. Saint-Jean Théristès (1054-1264), S. G. Mercati, C. Giannelli et A. Guillou (éd.), doc. 1.

20. Voir l'exemple pour les Pouilles: Martin, 1993, p. 293-301.

21. Certaines concessions matérielles faites par l'État byzantin à des personnes privées - complètement

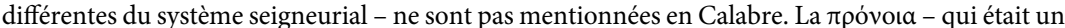
système établi dans l'Empire byzantin à partir du XI ${ }^{e}$ siècle - n'a pas touché le sud de l'Italie. Elle consistait en une exonération des taux d'imposition sur une terre à une personne privée, sans en

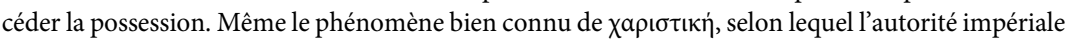
a accordé sur une base individuelle et temporaire la richesse d'un monastère à des notables laïcs, n'est pas documenté en Calabre - alors qu'il est attesté, en revanche, dans la Pouille méridionale. Voir Kaplan, 1992, p. 181 et p. 579-580; Peters-Custot, 2009a, p. 162-164 et p. 309, n. 10.

22. L'absence d'une haute aristocratie locale sur le territoire est remarquable. Voir MARTIN, 1999, p. 236, et sur les élites locales grecques Peters-Custot, 2009a, p. 164-167. En outre, l'absence totale de notables latins dans la partie supérieure du système seigneurial normand montre que même la partie septentrionale de la Calabre, à l'époque byzantine, était peuplée et gérée par les Grecs plus qu'on ne le pense, les élites latines d'origine lombarde étaient très faibles, même inexistantes (voir BERARDI, 2017a, chapitre II: La peculiarità della signoria calabrese: il periodo 


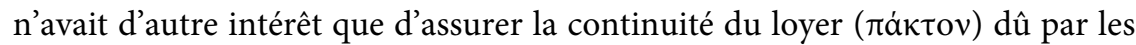

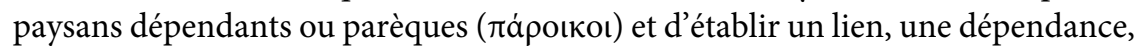
entre ces parèques et la terre. Comme l'écrit Michel Kaplan: «L'organisation des grandes propriétés est donc plus administrative que sociale et économique ${ }^{23}$. Ces parèques (та́)oเkol) ne sont pas mentionnés dans les documents calabrais de l'époque byzantine ${ }^{24}$, mais ils sont attestés au début de l'époque normande; par ailleurs, nous savons bien que, dans l'Empire byzantin en général, le phénomène des paysans non propriétaires qui s'installaient, en tant que rápoıkol, sur les territoires appartenant à des églises, des monastères ou des propriétaires laïcs était fort répandu et que les propriétaires ont ensuite demandé un permis pour régulariser leur situation. Ces permis ont été délivrés à la condition que

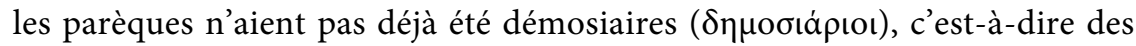
agriculteurs contribuables ${ }^{25}$.

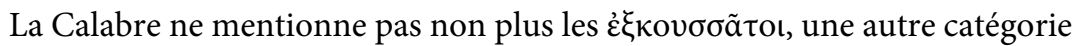
d'exploitants qui pouvaient bénéficier de conditions économiques favorables de la part de grands propriétaires terriens, et en particulier d'une exemption partielle ou totale des impôts secondaires, probablement en échange d'un cens à verser au propriétaire foncier ${ }^{26}$. Comme Jean-Marie Martin l'a clairement souli-

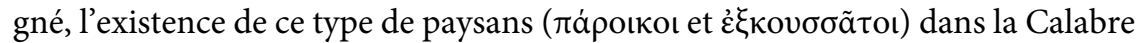
byzantine - dès le début du XI ${ }^{e}$ siècle - est évidente, en raison aussi bien de leur nécessité pour la grande propriété ecclésiastique que de l'importance des villani à l'époque normande ${ }^{27}$. Annick Peters-Custot a démontré du reste des formes de continuité dans les statuts paysans de la Calabre, entre les $\pi$ á potkot byzantins

pre-monarchico). Pour des exemples d'intégration de la Calabre dans le cadre administratif et

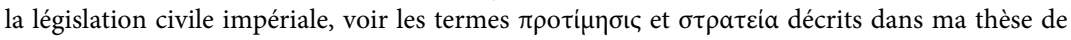
doctorat et pour les thèmes italiens, MARTIN, 2006. Au sujet des autres taxes documentées à la fois dans l'Empire byzantin et dans les thèmes italiens, on renvoie à MARTIN, 1993, p. 259 et p. 712 ; MARTIN, 2001, p. 492.

23. Kaplan, 1992, p. 159-169 et p. 182.

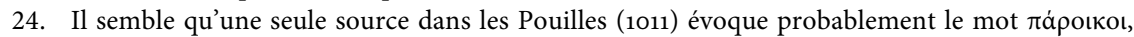
mentionné indirectement dans une traduction en latin d'un privilège grec, où apparaît le mot vaxalli de la cathédrale d'Oria. Comme l'a supposé Jean-Marie Martin, le mot vaxalli

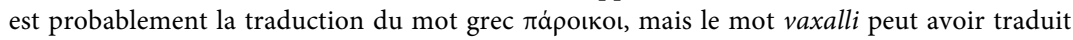
ăv $\theta \rho \omega \pi$ ot. Pour la source, voir Annibale De Leo, Codice diplomatico brindisino. I. (492-1299), G. M. Monti (éd.), I, doc. 2; pour l'interprétation voir Martin, 1993, p. 707 sq.; PetersCustot, 2015, p. 391.

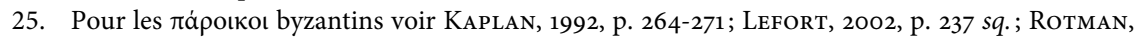
2000 ; Patlagean, 2008; Peters-Custot, 2017a. Un cas particulier vient de l'actuelle Basilicate où Kosmas, higoumène de la Théotokos du Refuge à Tricarico, a fait appel aux paysans qui avaient des obligations fiscales. Voir Guillou et Holtzmann, «Zwei Katepansurkunden aus Tricarico », p. 1-20.

26. Sur ce sujet voir Leicht, 1956; Kaplan, 1992, p. 554 sq.; Peters-Custot, 2009, p. 122; FAlKenHAUSEN, 2012, p. 545-547. Un exemple particulier est un $\sigma$ r $\gamma$ í $\lambda \lambda_{\text {เov }}$ de 1045 dans lequel le catépan Eustathe Palatinos a permis au juge Byzantius d'installer des paysans étrangers qui le souhaiteraient à Fugliano (Pouilles) et dans d'autres propriétés, avec la clause inhabituelle pour le droit byzantin, mais commune dans le formulaire lombard, que le juge exerce la basse

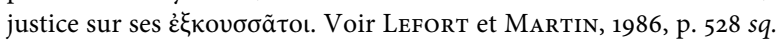

27. Martin, 2001, p. 499. 
et les paysans dépendants «normands ${ }^{28}$. En réalité, une si grande propriété est inimaginable sans ces parèques, et l'exemple du prêtre Paul de Seminara, qui a «tenu» 46 hommes pendant la période byzantine, est emblématique ${ }^{29}$.

\section{La Calabre comtale : avant la monarchie (1060-1130)}

\section{Seigneurie lä̈que et aristocratie de fonctions}

Avec la conquête normande, la grande propriété foncière de la région a été démantelée par les Normands - comme l'a montré Annick Peters-Custot dans son étude sur Bruno en Calabre ${ }^{30}$ - et redistribuée entre les membres de la nouvelle classe aristocratique normande qui a établi un régime seigneurial encore inexistant en Calabre même si, à certains égards, ce régime est semblable à la grande propriété byzantine ${ }^{31}$. Robert Guiscard, avec son frère le Grand Comte Roger, a conquis la Calabre: le centre et le nord ont été incorporés au duché de Pouille gouverné par Guiscard, le sud, joint à la Sicile (qui n'a été définitivement conquise que dans les dernières années du XI ${ }^{\mathrm{e}}$ siècle), a été confié à Roger $\mathrm{I}^{\mathrm{er} 32}$. Les différentes modalités de la conquête ont contribué à renforcer l'opposition entre le sud et le nord de la Calabre; les quelques différences qu'on peut y relever dureront jusqu'à l'époque souabe. Dans cet exposé, nous ne nous attarderons que sur le sud de la Calabre où la nouvelle société politique - contrairement à la Calabre ducale - était étroitement contrôlée par le Grand Comte ${ }^{33}$.

Dans la Calabre méridionale, la reconfiguration politique des élites est principalement fondée sur la nouvelle aristocratie «normande» bien que, comme nous le verrons, la vieille élite italo-grecque se soit intégrée au système administratif du comté calabrais ${ }^{34}$. Il semble que ce soit une pratique «normande» d'infiltrer les classes dirigeantes préexistantes, cela a également été démontré pour la Normandie par Pierre Bauduin ${ }^{35}$.

28. Peters-Custot, 2017a.

29. Cette source a été publiée par Falkenhausen, 2018, p. 1273-129o. Le document daté de 1111 expose que Roger II comte de Sicile et sa mère, la comtesse Adélaïde, ont confirmé au monastère de S. Maria de Bagnara la donation de 46 paysans qui avaient appartenu au prêtre Paul de Seminara,

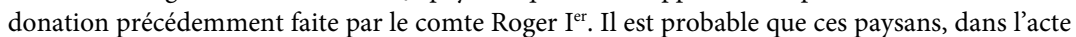

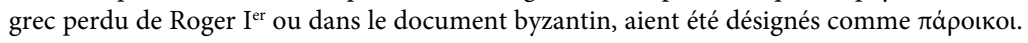

30. Peters-Custot, 2014a, p. 65 sq.

31. Martin, 2001, p. 498 sq.

32. Sur les modalités et les conflits de la conquête calabraise et sicilienne de Robert Guiscard, voir en particulier Guillaume de Pouille, La Geste de Robert Guiscard, M. MATHIEU, p. 245-278; Gaufredo Malaterra, De rebus gestis Rogerii Calabriae et Siciliae Comitis et Roberti Guiscardi Ducis fratris eius, E. Pontieri (éd.); Geoffroi Malaterra, Histoire du Grand Comte Roger et de son frère, Robert Guiscard, M.-A. LuCAs-Avenel (éd. et trad.); Loud, 20oo, p. 92 sq., p. 146 sq.

33. Pour l'histoire de la Calabre ducale, voir BERARDI, 2017, chapitre II: La peculiarità della signoria calabrese: il periodo pre-monarchico.

34. Surtout les familles Maleinos et Moschatoi. Sur cette intégration voir Peters-Custot, 2009a, p. 401 sq.; Peters-Custot, 2012a.

35. Bauduin, 2005; Bauduin, 2009. Pour l'infiltration dans le sud de l'Italie, voir Ménager, 1991a, p. 203-229; MÉNAGER, 1991b, p. 279-410; LOUD, 2019, p. 339-358. 
La grande aristocratie seigneuriale importée, qui - à l'exception de quelques cas minoritaires - ne disposait pas de droits publics, se distinguait de la classe moyenne, à la fois par sa proximité avec le Grand Comte (Roger Ir) et par l'importance quantitative de ses propriétés foncières. Ce n'est que plus tard, pendant la régence de la veuve de Roger I ${ }^{\mathrm{er}}$, Adélaïde $(1101-1118)^{36}$, que la famille Borrel acquit - sans rébellion - plus de pouvoir, mais elle revint bientôt sous le contrôle de Roger $\mathrm{II}^{37}$. Les autres aristocrates fidèles à Roger I ${ }^{\text {er }}$ et à Roger II, tels que Josbert de Lucy, Eudes le Bon Marquis ${ }^{38}$, Guillaume Culchebret et Guillaume de Hauteville, ont établi des seigneuries qui dureront bien après leur mort - celle de Culchebret jusqu'à l'époque moderne ${ }^{39}$. Les familles de la nouvelle noblesse «normande» de la Calabre méridionale - du moins certaines d'entre elles - ont joui d'une longévité supérieure à celle des familles installées dans les Pouilles ${ }^{40}$; malgré tout, la relation entre le pouvoir souverain et l'aristocratie - même à l'époque monarchique, à partir de 1130 - n'était pas totalement négative.

L'aristocratie moyenne avait une propriété rurale de taille également moyenne, et faisait quelques donations pieuses aux institutions religieuses locales (la famille la plus importante était celle des Carbonel) - la grande et la moyenne aristocratie avaient des relations étroites avec la Sicile. La basse aristocratie était composée de milites, mais les sources conservées montrent qu'elle était plutôt petite par rapport à la partie nord de la région, dans le duché de Pouille où la guerre était endémique, car Roger $I^{\text {er }}$ avait rapidement établi un "état de paix " dans la Calabre méridionale. Enfin, une catégorie sociale a été créée entre la moyenne et la petite aristocratie, c'est essentiellement une aristocratie de fonctions - mais cela n'a certainement pas contribué au service militaire - composée principalement des agents italo-grecs de la cour de Roger $\mathrm{I}^{\mathrm{er}}$, fondamentale pour le fonctionnement de l'appareil bureaucratique et qui constituait la base de la future structure administrative de la monarchie.

Ce qui différenciait ces fonctionnaires des agents de la petite élite des territoires principalement gérés par l'administration comtale et seigneuriale ne reposait pas sur un critère exclusivement économique, car les sources ne permettent pas de donner une valeur précise au patrimoine de ces individus ${ }^{41}$;

36. Falkenhausen, 1998

37. Il semble que la famille Borrel soit d'origine lombarde. Les frères Guillaume, Roger et Robert Borrel possédaient les châteaux de Borrello - peut-être une fondation du seigneur du même nom -, S. Giorgio et Rocca di S. Mena sur le territoire des Salines; toutefois seul Robert est devenu le plus grand aristocrate du sud de la Calabre. Un autre frère, Geoffroy, avait, en revanche, une grande seigneurie dans le nord-est de la Sicile (dans la vallée de Milazzo). Pour plus d'informations voir BECKER, 2008a, p. 96-99 et BERARDI, 2017, chapitre II: La peculiarità della signoria calabrese: il periodo pre-monarchico, où sont présentées toutes les sources citant la famille Borrel en Calabre.

38. Sur cet aristocrate, voir infra.

39. Sur ces familles et sur d'autres grands aristocrates, voir BERARDI, 2017, chapitre II: La peculiarità della signoria calabrese: il periodo pre-monarchico.

40. Pour la situation de la Pouille, voir Martin, 1993, p. 719 sq., p. 769 sq.

41. La petite élite comprenait aussi des agents des territoires comtaux et seigneuriaux, principalement italo-grecs (voir BERARDI, 2017, p. 56-61), ainsi que les plus importantes familles italo-grecques 
leur prééminence était due à la proximité avec Roger $\mathrm{I}^{\mathrm{er}}$ sans la médiation d'un autre aristocrate. Parmi les plus importants, il y a le notaire gréco-calabrais Bonos attesté à la cour du comte entre 1083 et $1117^{42}$. Bonos reçut du Grand Comte des pouvoirs étendus dans le comté de Calabre, comme le titre de magnus iusticiarius tocius Calabrie et magne curie le confirme ${ }^{43}$, et il a également été récompensé par la dignité impériale de $\pi \rho \omega \tau o v o \beta \varepsilon \lambda \lambda i \sigma \sigma \mu \varsigma^{44}$.

Les droits seigneuriaux et la «féodalité» à l'époque pré-monarchique étaient très précaires dans toute la région. Dans la Calabre méridionale, en revanche, le pouvoir comtal a, tout au long de la période comtale, tenu en monopole toute l'autorité publique en imposant un régime très contrôlé et administratif, et en excluant l'héritage systématique des seigneuries. Le Grand Comte, héritier de la puissance publique byzantine, a organisé le territoire en petites seigneuries foncières autour de sa première capitale, Mileto, conservant un vaste domaine comtal cultivé par de nombreux villani; cette particularité historique de la seigneurie calabraise (au nord comme au sud de la Calabre) a prolongé la grande propriété ecclésiastique bien attestée à l'époque byzantine. Les seigneurs normands se sont approprié de grandes réserves agricoles, comme en témoigne l'apparition - très répandue dans la

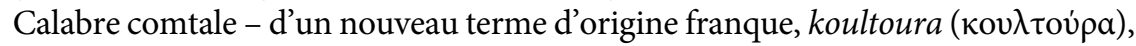
qui désignait un champ relativement important de la réserve seigneuriale ${ }^{45}$. Pour la construction économique et foncière de la domination, ont également été rédigés

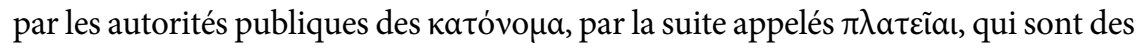
inventaires d'hommes «détenus» par Roger I ${ }^{\mathrm{er}}$, parfois donnés à des institutions ecclésiastiques et à des seigneurs laïques, et servant à contrôler la population et éventuellement à demander des corvées publiques et militaires qui revenaient au comte $^{46}$. Ce sont donc des listes d'hommes de tous statuts qui paient un loyer au

d'origine byzantine, qui ont maintenu pendant toute la période normande un rôle fondamental dans l'administration de la Calabre méridionale, en préservant parfois leurs dignités impériales, spécialement dans les zones fortement hellénisées comme Stilo, Squillace et Gerace (Voir PETERsCustot, 2009a, p. 402 sq. ; Peters-Custot, 2012a; Peters-Custot, 2012b, p. 643-658). De cette façon, Roger I ${ }^{\text {er }}$ a créé une forme de consensus, d'adhésion et de participation des communautés conquises pour maintenir un état de paix.

42. Sur le notaire Bonos voir Falkenhausen, 2009, p. $178 \mathrm{sq}$.

43. Probablement - comme l'a bien noté Jean-Marie Martin - l'existence du juge du thème byzantin a inspiré la naissance des grands juges ou justiciers de la Calabre, puis du royaume normand. Voir MARTin, 2001, p. 514.

44. Sur ce titre, voir Peters-Custot, 2012b. Vera von Falkenhausen rapporte que Bonos, comme l'émir Christodoule, a obtenu la dignité impériale de l'empereur Alexis Ir peut-être parce qu'il s'était engagé à isoler Bohémond lors de ses initiatives anti-byzantines (FALKENHAUSEN, 2009, p. 179-18o). Cependant, je pense qu'il ne faut pas oublier que Robert Guiscard a reçu un certain nombre de dignités à distribuer qui furent transmises probablement après sa mort à son frère Roger $I^{\text {er }}$ qui les a distribuées à son tour. Voir aussi BiBICOU, 1959-1960.

45. À propos de ce terme en Calabre, voir MARTIN, 2001, p. 508.

46. Ces corvées publiques et militaires qui revenaient au comte étaient clairement d'origine byzantine; nous en avons des exemples indirects à cette époque, par exemple: la muratio castelli (voir MARTIN, 2001, p. 509-510) et le ius lignaminum (voir infra). D'autres corvées publiques, telles que le service militaire, sont aussi attestées; le cas de Badolato est emblématique: un document de 1165 (Syllabus graecarum membranarum..., F. Trinchera [éd.], doc. 167) définit un litige judiciaire entre Landrino, des ermites de S. Stefano del Bosco, et les capitaines (кó $\mu \tau \varepsilon \varsigma$ ) des 
propriétaire, et sans doute leur concession à un puissant est-elle non pas l'effet d'un statut de dépendance personnelle, mais un trait de fiscalité publique (bref, cela correspond au système byzantin, à la fois des parèques, et de la $\pi \rho o ́ v o เ a)$ : les hommes recensés doivent payer leur impôt au seigneur foncier bénéficiaire

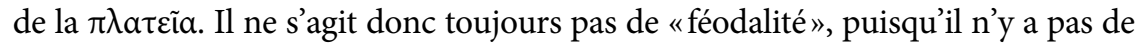
privatisation des droits et de l'autorité publics, mais transfert de revenus fiscaux. Le rapport à la terre est donc forcément différent pour les seigneurs, dont l'autorité se borne à une dimension foncière.

L'origine de ce type de sources a été récemment étudiée par Annick PetersCustot, mais au terme de l'analyse minutieuse de l'historienne française, il semble qu'il soit impossible de savoir avec assurance si on a pris pour modèle des documents gréco-calabrais influencés par Byzance ou s'ils sont une création de la Sicile normande ${ }^{47}$; d'autre part, à mon avis, il est peu probable que les Normands aient complètement inventé de telles listes ${ }^{48}$. En outre, à ce stade, on peut également supposer, sur la base de la documentation examinée et surtout grâce à l'étude d'Annliese Nef qui a identifié une continuité entre le système fiscal byzantin et celui de la Sicile arabo-musulman ${ }^{49}$, que les «listes d'hommes » siciliennes et calabraises étaient une pratique administrative byzantine datant

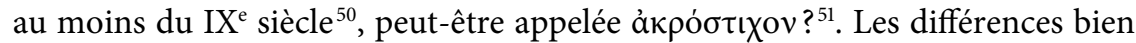
décrites par Annick Peters-Custot entre les $\pi \lambda \alpha \tau \varepsilon i a$ c calabraises et les jarâ’id siciliennes ${ }^{52} s^{\prime}$ expliquent probablement grâce à la comparaison faite par là même entre $\pi$ á arabes étaient peut-être plus indépendants à l'époque islamique ${ }^{54}$ ? De plus,

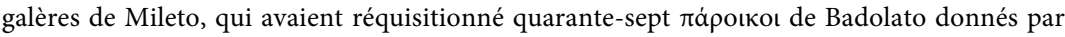
Guillaume Carbonel en 1118 au monastère (acte perdu, mentionnant des corvées publiques). Les capitaines de Mileto avaient confisqué ces hommes pour en faire des marins et augmenter les forces navales royales (pour l'interprétation de la source, voir Peters-Custot, 2014a, p. 122-126).

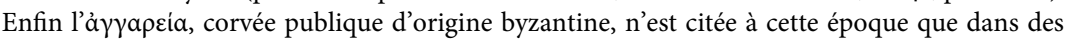
falsifications et est étroitement liée à l'état ultérieur d'angararius. Voir OıKonOMIDÈs, 1996, p. 105.

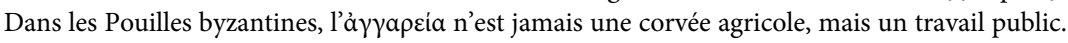
Voir Martin, 1993, p. 302 et p. 712.

47. Peters-Custot, 2015.

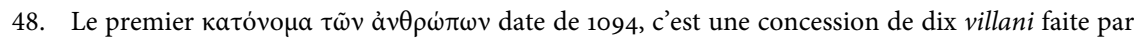
Roger $\mathrm{I}^{\mathrm{er}}$ aux ermites de S. Bruno. Voir Documenti greci e latini di Ruggero I di Calabria e Sicilia, J. Becker (éd.), doc. 44. Voir aussi Peters-Custot, 2014a, p. 83 sq. Pour d'autres exemples, voir MARTIN, 2009.

49. NEF, 2000.

50. Pour les jarâ'id siciliennes et pour les différences avec la Calabre à cause des populations musulmanes voir Nef, 200o, p. 586-589; Petralia, 2006, p. 238 sq. ; Peters-Custot, 2015. Nous avons d'autres exemples indirects de pratiques byzantines dans la Sicile arabe puis dans la Calabre

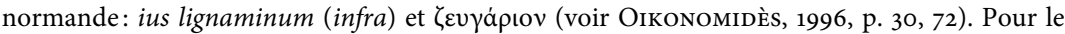

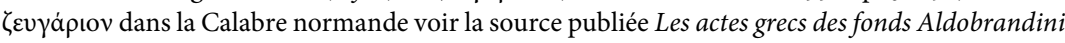
et Miraglia (XI ${ }^{e}$-XIII ${ }^{e}$ s.), A. Guillou (éd.), doc. 26.

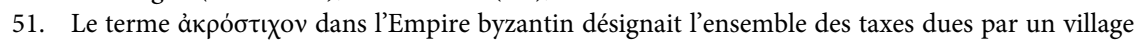
(voir Oikonomidès, 1996, p. 55 sq.). Le terme n'est utilisé, au moins à ce stade de la documentation, qu'une seule fois en Calabre (ducale). Voir Falkenhausen, 2013, doc. 7.

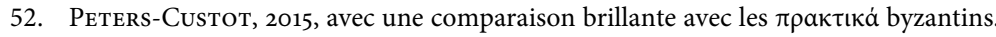

53. Peters-Custot, 2017 a.

54. Nef, 2011, p. 463 sq. Voir aussi Metcalfe, 2009, p. 112 sq. 
seules les listes du nord-est de l'île, où la population était majoritairement grecque, énumèrent parfois le travail agricole des « hommes des listes ${ }^{55}$, comme en Calabre depuis le XII ${ }^{\mathrm{e}}$ siècle. Les Arabes en Sicile ont sûrement modélisé ces listes, ainsi que plus tard les «Normands» en Calabre et en Sicile même ${ }^{56}$. Il semble certain que le terme platea a été inventé par les Normands ${ }^{57}$.

Comment la seigneurie a-t-elle été administrée? La perception des impôts dans les deux «Calabres» était faite par des agents, qui pouvaient être seigneuriaux ou au service du Duc ou du Grand Comte, les principaux étant les $\sigma \tau \rho a \tau \eta \gamma o i ́$,

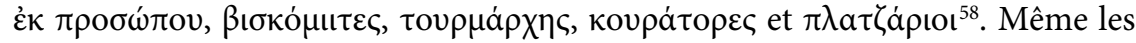
terres incultes utilisées pour le pâturage, le bois et les terrains de chasse ont été incorporées dans les nouvelles seigneuries, les propriétaires percevaient des revenus sur la pêche et le commerce maritime ${ }^{59}$. La privatisation des droits publics est presque complètement absente: les dîmes sur les revenus privés, absentes dans l'Empire byzantin, ne sont pas introduites par les Normands ${ }^{60}$, les banalités sur les moulins, les fours et les pressoirs ne sont presque pas attestées ${ }^{61}$, de même que les

55. Voir Petralia, 2006, p. 245

56. Alessandro Di Muro (Di Muro, 2018) a souligné aussi la présence de listes d'hommes et de terres dans les ex-principautés lombardes et dans le duché de Pouilles déjà à l'époque prémonarchique, surtout pour le prélèvement fiscal. Mais, à mon avis, cela n'affecte pas l'originalité du comté de Sicile. Qu'il existe des obligations envers l'État dans les principautés lombardes a déjà été prouvé (voir MARTin, 2005, p. 139 sq.; LORÉ, 2013; LORÉ, 2019, p. 68 sq.), ainsi que la présence de listes de personnes dans les zones du duché, comme pour les affidati dans les Pouilles (voir MARTIN,

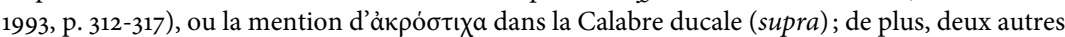
aspects doivent être pris en compte. Il a d'abord été montré comment l'Empire byzantin a servi sous certains aspects de modèle aux principautés lombardes (voir MARTIN, 2005, passim), même si le système bureaucratique était moins précis; et il se pourrait même que les principautés aient pris comme modèle des listes d'hommes de la Calabre byzantine voisine? Enfin, contrairement à la Calabre et peut-être à la Sicile, il semble que la seigneurie qui s'est développée à l'époque normande dans les ex-principautés repose principalement sur des droits sur la terre et dans une moindre mesure sur la fiscalité des hommes.

57. Un changement fondamental à l'époque monarchique est enregistré dans la rédaction des platee. Il existe encore des inventaires publics (comme celui de Badolato du comte de Catanzaro. Voir Syllabus graecarum membranarum..., F. Trinchera [éd.], doc. 167), mais dès la seconde moitié du $\mathrm{XII}^{\mathrm{e}}$ siècle - et surtout au XIII ${ }^{\mathrm{e}}$ siècle - les églises et monastères, après avoir reçu des concessions, ont compilé pour leur compte des inventaires précis tant des hommes soumis que des corvées et de la propriété foncière. Les platee, d'inventaires publics, devinrent ainsi des instruments de gestion privée des hommes des grands propriétaires. Une liste de tous ces inventaires est donnée dans BERARDI, 2017, chapitre III: La peculiarità della signoria calabrese: il periodo monarchico.

58. La perception de la $\pi \lambda a ́ \tau \zeta \alpha$ (plateaticum, taxe commerciale indirecte équivalente au teloneum des anciennes régions carolingiennes), le plus important parmi les droits publics, confiée au $\pi \lambda \alpha \tau \zeta \dot{\alpha} \rho$ เoৎ, n'apparaît que dans des documents de l'époque normande, mais la $\pi \lambda \dot{\alpha} \tau \zeta \alpha$ est déjà mentionnée dans un document de 1034 du catépan byzantin d'Italie Constantin Opos (Syllabus graecarum membranarum..., doc. 28), étant donné que, probablement, le système fiscal byzantin n'avait pas encore été défini.

59. Pour plus d'informations voir supra note 38 et les sources énumérées dans BerARDI, 2017, chapitre II: La peculiarità della signoria calabrese: il periodo pre-monarchico.

60. Sur les dîmes, voir Peters-Custot, 2014a, p. 67.

61. Il n'y a qu'un seul cas où la femme d'Eudes le Bon Marquis, Sikelgaita, probablement une lombarde, est titulaire du droit de moudre dans des moulins (molitura molendini) à S. Caterina (aujourd'hui S. Caterina dello Jonio); ce pourrait être une interpolation, mais nous ne pouvons pas nous exprimer sur l'authenticité, car le document ne nous est parvenu que dans le travail de 
droits de justice qui, dans la partie sud de la région, étaient collectés uniquement par la bureaucratie comtale ${ }^{62}$. Ce système administratif de la seigneurie a aussi certainement contribué à la construction de la paix sociale.

Enfin, l'épineuse question des relations vassaliques et du féodalisme. L'historiographie récente a fortement remis en question les relations vassaliques traditionnelles et l'existence même des termes de fief et de féodalisme également du point de vue heuristique ${ }^{63}$ : pour l'Italie méridionale, la question a été abordée par Sandro Carocci, qui a déplacé la «féodalisation» du Royaume de Sicile à l'époque souabe ${ }^{64}$, nous reviendrons sur ce sujet.

En ce qui concerne les relations vassaliques, il faut noter que pour l'époque pré-monarchique (donc avant 1130), les mots vassallus et fidelis ne sont presque jamais attestés ${ }^{65}$; le fief semble être une rareté, et dans le sud de la Calabre il n'est jamais mentionné ${ }^{66}$, alors que nous en avons des attestations dans le nord de la région. Dans deux des occurrences, le terme latin est attesté aussi dans

Benedetto Tromby. Dernière édition de la source dans Documenti dell'Eremo della Torre e del monastero di Santo Stefano del Bosco (secc. XI-XIII), F. IAntorno (éd.), doc. 42. Sur ces éditions de sources voir les critiques, fondées, dans Peters-Custot, 2014a, p. 31, n. 75.

62. Cependant, certains aspects doivent être pris en compte: en raison du regain d'intérêt pour les territoires méridionaux de Roger Borsa et du retrait de la Calabre, il est supposé qu'Adélaïde a accordé de petites prérogatives publiques aux grands aristocrates pour assurer l'ordre et la loyauté. Robert Borrel semble avoir eu une sorte de protectorat sur le comté de Calabre en dépit du fait que dans une source, le duc Roger Borsa soit mentionné comme autorité suprême; de plus, il a tenu à percevoir le plateaticum et d'autres taxes. De même Josbert de Lucy avait des prérogatives dans la construction de moulins près de Patterano en Sicile et de Stilo, et sa seigneurie est devenue héréditaire après avoir été divisée après sa mort entre sa femme et son fils Barthélemy; Eudes le Bon Marquis, dans son $\sigma$ r $ү \hat{\lambda} \lambda \lambda_{\mathrm{\iota}} \mathrm{v}$, définissait ses territoires ex iurisdictione mea, il avait à son service des agents. Tous ces aristocrates avaient la capacité de transmettre le pouvoir seigneurial à travers les générations et de l'utiliser pour la politique familiale en agissant sans fortes contraintes extérieures (voir BERARDI, 2017, chapitre II: La peculiarità della signoria calabrese: il periodo pre-monarchico). En ce qui concerne les droits de justice, nous ne savons presque rien à l'époque pré-monarchique, probablement parce que - comme l'a noté Jean-Marie Martin - les documents d'archives qui nous sont parvenus, qui servaient essentiellement à préserver la mémoire des propriétés ecclésiastiques, attestent parfois des procès civils, mais presque jamais des poursuites pénales. Voir Martin, 1997, p. 184.

63. Voir Albertoni et Provero, 2003, dans lequel est contestée l'abstention dans le débat de Wickнам, 2000 ainsi que les hypothèses négationnistes de GUERrEAU, 1980 et REYNOLDS, 1994. Voir aussi Brown, 1974, p. 1063-1088.

64. CAROCCI, 2014, p. 140 et passim. Sur le sujet voir aussi Loud, 2014; VARANINI, 2018.

65. Il n'y a que deux cas sur lesquels on pourrait émettre des hypothèses de relations vassaliques: Robert de Montepeloso (aujourd'hui Irsina), dans un document non daté, a fait une concession avec l'accord du dominus meus Guillaume Culchebret (MÉnAger, 1958-1959, doc. 12); à la suite de Sikelgaita marchisia, le notaire Arcadius l'appelait domina mea. Voir Syllabus graecarum membranarum..., doc. 98. Enfin, Malaterra, dans son œuvre, emploie aussi le terme homo dans le sens de «vassal», semble-t-il: pour Ingelmar (III, 31: comes, legalitatem suam servans, hactenus homini suo diffidentiam in posterum mandat) et pour Mihera, "homme» de Bohémond (IV, 9: [Mihera] Suis autem viribus auxilia addere volens, Boamundi, fratris ducis, qui jam, foedere rupto, adversus fratrem conspiraverat, homo efficitur), comme me l'a indiqué Marie-Agnès Lucas-Avenel (Craham, Université de Caen Normandie). Voir Geoffroi Malaterra, Histoire du Grand Comte Roger... (Livres III \& IV), M-A. LuCAs-Avenel (éd.).

66. Le mot latin feudum ne se trouve que dans une copie latine du XVII ${ }^{\mathrm{e}}$ siècle d'un original grec perdu de 1071, concernant la donation d'un monastère dédié à Saint Basile le Grand (Torre di 
une transcription grecque sous la forme $\varphi \operatorname{lov}^{67}$; le terme dominus est rendu en

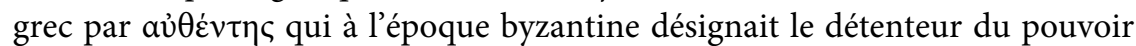
impérial ${ }^{68}$. Roger I $^{\text {er }}$ - puis Roger II - en utilisant le grec plutôt que le latin dans leurs documents, montrent une continuité avec le domaine socio-politique précédent, construisant ainsi grâce à une politique linguistique un état de paix avec les populations locales ${ }^{69}$.

La grande aristocratie ne semble pas être particulièrement faible, mais aucun document ne nous renseigne sur la capacité de prélèvement et les stratégies patrimoniales des aristocrates, à l'exception des pratiques d'alliance matrimoniale: les nobles les plus importants se sont mariés avec les filles et nièces du Grand Comte ou du Duc ${ }^{70}$.

La question de l'origine de la "féodalité » à l'époque pré-monarchique (donc durant l'époque comtale, entre 1060 et 1130) est complexe, mais certaines sources m'ont permis de confirmer une hypothèse qui avait été précédemment

Ruggiero, province de Catanzaro), ce qui est certainement une interprétation du traducteur : dans la même source est évoqué nemus seu feudum. Voir Breccia, 1991, p. 14-105, doc. 1.

67. Il s'agit de l'invention d'un mot grec inexistant dans le vocabulaire grec médiéval, et calqué sur le latin, ce qui atteste bien qu'on a dû faire de l'innovation lexicale pour traduire un phénomène

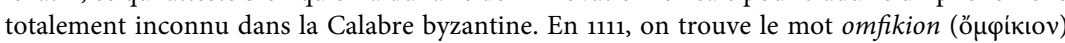
dans une donation de Roger II à S. Maria del Patir (près de Rossano) de l'église de S. Apollinara, mais il s'agit certainement d'une erreur du copiste du mot grec phidion ( $\varphi$ í $\delta$ เov), utilisé pour décrire un fief à Brahalla (aujourd'hui Altomonte). Voir BrecciA, 2005, doc. 2. Le mot phaion apparaît en 1115 dans un document attestant un don près de San Marco (aujourd'hui San Marco Argentano): Roukaris, fils de Turgisius de Rota, avait reçu un phaion du duc Guillaume (voir Les actes grecs des fonds Aldobrandini et Miraglia [XI ${ }^{e}-X I I I^{e}$ s.], A. GuIllou [éd.], doc. 33). Pour le píov du Marescotto détenu à l'âge pré-monarchique, voir infra. Le mot latin se trouve en 1118 ( $f e v u m$ ) dans la zone située entre Corigliano et Rossano, dans la description du territoire susmentionné de Losdum; toutefois, la source est une copie de l'original et comporte plusieurs interpolations. Voir Berardi, 2015a, p. 26. Dans la Sicile voisine, il semble qu'il y ait deux attestations: une traduction latine d'un acte grec perdu de 1115 rapporte une concession par Roger ${ }^{\mathrm{er}}$ au miles Gautier Gavarretta d'un pheudum casalis dicti de Sicamino (Gualtieri Sicaminò), qui était composé d'un bois, d'une église, d'un moulin et un musulman avec ses descendants (voir I documenti inediti dell'epoca normanna. Parte prima, C. A. GARUFI, doc. 4). En 1121, Raul, dominus de Cefalù, concéda en fief à un certain Guiscard, fils de Baudouin, six villageois arabes avec un lopin de terre. En échange, Guiscard devait donner 50 tarì et un cheval. Voir GARUFI, 1928, doc. 1.

68. Cependant, cette terminologie n'est pas présente dans la Calabre comtale (sauf pour le Grand Comte et Roger II); dans un seul exemple seulement on cite Guillaume Capriol comme

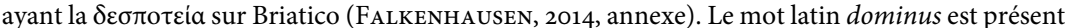
en référence à Barthélemy de Lucy, Guillaume Carbonel, Culchebret et Sikelgaita marchisia. Voir BERARDI, 2017, chapitre II : La peculiarità della signoria calabrese: il periodo pre-monarchico. Sur

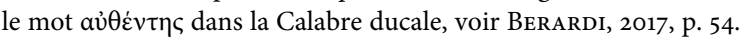

69. Peters-Custot, 2018a, p. 293-313.

70. Par exemple, Josbert de Lucy et Roger Barneville se sont mariés avec des parents du grand comte. Josbert de Lucy a épousé Muriel (fille de Roger), tandis que Guillaume de Grandmesnil a épousé Mabilia, fille de Robert Guiscard (voir DecAËNs, 1994, p. 136). Quant à Roger de Barneville, il n'est pas certain que son épouse, nommée Eloisa, ait été la fille de Serlon (neveu de Roger de Hauteville), comme l'a pensé Julia Becker (voir BECKER, 2008a, p. 95, 108), car l'analyse semble se fonder sur une mauvaise identification de Gerace (Geoffroi Malaterra III, 31). Je remercie Marie-Agnès Lucas-Avenel (Craham, Université de Caen Normandie) pour m'avoir signalé cette question. 
avancée $^{71}$, à savoir que les fiefs / phia existaient déjà, même si les informations documentaires qui nous sont parvenues sont rares et proviennent d'institutions religieuses. Il semble aussi que - comme l'a montré Sandro Carocci - les différences entre un fief et une terre en pleine propriété existent mais sont très minces $^{72}$. La similitude est également presque la même dans la demande de service militaire par le Grand Comte et plus tard par le roi. Par conséquent, le problème reste de savoir pourquoi est utilisé dans les sources - rares au XIe siècle mais plus visibles depuis le $\mathrm{XII}^{\mathrm{e}}$ - le terme piov $^{73}$. Ce qui semble certain, en se fondant sur la documentation postérieure, c'est qu'un piov (pour lequel était dû le service militaire) n'était jamais un territoire entier, cela pouvait aussi être un simple vignoble, ou le contrôle des hommes, nous reviendrons sur le sujet. Donc le rôle de la «féodalité» et de la seigneurie dans le passage de la conquête à la construction étatique fut sans doute présent mais pas fondamental ${ }^{74}$.

\section{La seigneurie ecclésiastique}

Quel a été le rôle de la seigneurie ecclésiastique dans la construction de la nouvelle paix étatique? Les Normands (contrairement à ce qui a pu être avancé) ne remplacent jamais de force aucun prélat, mais dans la partie méridionale de la Calabre, le siège de la métropole de Reggio est rapidement confié à un évêque latin (le métropolite grec, Basile, étant particulièrement peu ouvert aux nouveaux maîtres du territoire $)^{75}$, tandis que les possessions de la métropole sont démembrées et concédées aux aristocrates et aux nouvelles institutions monastiques; dans le nord de la Calabre, seul l'évêque grec de Cassano fut déposé pour rébellion contre Robert Guiscard ${ }^{76}$.

Même dans le domaine ecclésiastique, une distinction doit être faite entre les deux «Calabres»: dans le sud de la Calabre et en Sicile, se pose la question de la

71. Voir supra et par exemple les livres d'Errico Cuozzo, en particulier Cuozzo, 1995b et Cuozzo, 2008, p. 143 sq. bien que l'auteur comprenne la plupart des patrimoines aristocratiques comme des fiefs.

72. CAROCCI, 2014, p. 109 et passim.

73. Voir infra.

74. Récemment, les recherches sur la Normandie et l'Angleterre normande ont cessé de considérer ces régions comme complètement féodales (les Normands en auraient tiré le système féodal destiné à être importé dans le sud de l'Italie). Les institutions étiquetées féodales se sont lentement stabilisées. Déjà dans un article important, John Prestwich avait souligné que la partie importante du système militaire normand en Angleterre n'était pas un «service féodal», mais un service rémunéré (Prestwich, 1954, p. 19-43, je remercie Graham Loud [Université de Leeds] de m'avoir signalé cet article). Voir Gillingham, 2000, p. 187-206; Bauduin, 2004, p. 216 sq.; Bauduin, 2008, p. 62-69. Pour l'histoire de la Normandie et de l'Angleterre normande dans cette période, voir Bates, 2013; Molyneaux, 2015; Green, 2017; Hagger, 2017. Pour le sud de l'Italie toutes les études « régionales» sur la période normande ont montré qu'à l'époque pré-monarchique, le terme de feudum était tardif et rare et que vassallus désignait surtout des paysans. Voir Martin, 1993, p. 754-762; FelLER, 1997; SKINNER, 2000; NEF, 2011, p. 446-447. Enfin le livre de CAROCCI, 2014, p. 120-127.

75. Sur Basile, métropolite de Reggio, voir Stiernon, 1964

76. Voir Peters-Custot, 2009a, p. 233-306. 
fameuse légation apostolique, accordée par un privilège d'Urbain II en 1098, qui permettait au Grand Comte d'agir comme légat (vice legati) du pape ${ }^{77}$; même dans cette partie de la région, la «latinisation » de certains sièges épiscopaux stratégiques fut entreprise par les premiers seigneurs normands, mais on attendait la mort du prélat grec pour le remplacer par un latin, comme ce fut le cas à Squillace à la mort du dernier évêque grec, Théodore Mésimérios. Aux nouveaux évêques latins étaient confiés de manière très officielle les prêtres byzantins, hommes mariés et souvent pères de famille, et le comte maintint fermement l'idéologie byzantine qui faisait des évêques les «gardiens» de l'Église d'État ${ }^{78}$. Les chefs normands étaient les principaux acteurs des nominations épiscopales, même si le rôle des forces locales et du Saint-Siège ne doit pas être négligé ${ }^{79}$; sauf pour l'archevêque de Palerme, qui avait un rôle politique, et pour l'évêque de Mileto, de la famille de Lucy, aucun grand prélat ne venait de familles aristocratiques, et beaucoup venaient de Normandie ou de Touraine ${ }^{80}$.

Nous avons pu établir, grâce à la documentation, une hiérarchie des évêques et des biens de leurs diocèses; dans la Calabre comtale les sièges les plus prestigieux étaient ceux de Rossano et de Santa Severina situés dans le nord de la région ${ }^{81}$; les principales seigneuries épiscopales documentées sont latines (comme Mileto) ou passées à un prélat latin (comme Squillace et la métropole de Reggio); dans ces deux cas, les territoires où résidait l'évêque étaient presque toujours «domaniaux». En ce qui concerne les droits seigneuriaux, le Grand Comte a confié aux monastères des droits purement matériels et économiques, et les cathédrales, qui, presque toutes, possédaient déjà des biens immobiliers étendus, une juridiction sur

77. FODALE, 1970. Voir aussi Loud, 2007, chapitres 2 et 9.

78. Peters-Custot, 2009a, p. 249-250. Voir aussi Martin, 2016, p. 5-22. Pour le rôle des évêques à Byzance voir Moulet, 2011, en particulier p. 399 sq. Le récent article de Antonio Macchione (MAcchione, 2017) présente plusieurs erreurs tant dans la lecture des sources que dans la méthode. Pourquoi citer La Vie de Nil de Rossano non pas dans l'édition critique du texte grec

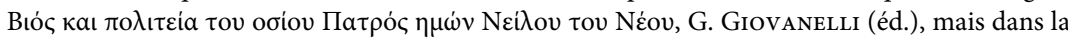
traduction italienne, du même, en 1966 ? Une erreur importante dans le texte qui accompagne la note 8 : on mentionne en fait la «diataxis» de Basile le Grand, qui n'a également rien à voir avec les typika mentionnés dans la note (note 8, qui ignore aussi totalement la publication à Dumbarton Oaks des tipika byzantins). De plus, l'article reprend la discussion sur la «latinisation » de l'Église italo-grecque et sur le «schisme» de 1054 (note 61) sans tenir compte des récentes recherches de Michel Kaplan, Gilbert Dagron et surtout d'Annick Peters-Custot. Enfin, il semble absurde que le monastère féminin de Cosenza $S$. Maria Ancillarum, dépendance de Cassino du IX ${ }^{\mathrm{e}}$ siècle, ait étendu son influence dans des «loca in finibus Beneventanis et in Apuliis et Kalabricis» (p. 341). La lecture des sources papales citées par Paul Fridolin KEHR, Le bolle pontificie anteriori al 1198 che si conservano nell'Archivio di Montecassino, p. 30-32 (note 243) et du registre de Pierre Diacre (Registrum Petri Diaconi [Montecassino, archivio dell'abbazia, reg. 3], J.-M. MARTIN et al. [éd.], doc. 8, 13-16) apparaît complètement erronée.

79. Pour la situation en Sicile et Calabre voir BECKER, 2008b, p. 24 sq. et dans le futur royaume Loud, 2007, p. 364 sq.; PANARelli, 2019, p. 200-203.

80. Voir BERARDI, 2017a, chapitre II : La peculiarità della signoria calabrese : il periodo pre-monarchico et Cuozzo, 1995a.

81. Ces diocèses, inclus géographiquement dans la Calabre ducale, ont été soumis après la mort de Guiscard au pouvoir du comte. Voir BERARDI, 2017a, chapitre II: La peculiarità della signoria calabrese: il periodo pre-monarchico. 
les juifs et des exonérations fiscales, reçurent, pour accroître leurs revenus, la dîme sur les droits publics (ou decima) sur l'ensemble du diocèse, parfois seulement sur la ville épiscopale ${ }^{82}$. Pour certaines cathédrales (par exemple Mileto), les sources citent d'importantes prérogatives publiques, mais, comme pour les monastères, la majorité des documents sont des copies d'époque moderne ${ }^{83}$; en l'absence de documents qui confirment leurs droits réels ou supposés, des faux furent composés durant les périodes de faiblesse de la puissance publique afin d'appuyer des revendications en cas de contestation ou pour obtenir des confirmations ${ }^{84}$.

Les droits seigneuriaux du diocèse de Squillace sont bien documentés et méritent attention. Le dernier évêque grec, Théodore Mésimerios, est un important représentant du «système normand »: il apparaît immédiatement dans des diplômes comtaux de la région, recevant également des possessions $\mathrm{du}$ Grand Comte ${ }^{85}$. On a conservé une offrande qu'il a faite à S. Maria de Turri concernant de petits champs, des terres non cultivées et un moulin à eau, il a ensuite exempté les moines du paiement du dekaton ${ }^{86}$, terme qui - comme l'a montré Annick Peters-Custot - semble avoir été créé pour traduire le lemme latin de "decima»; c'est probablement un droit que l'évêque avait déjà à l'époque byzantine $^{87}$. À l'Archivio di Stato de Naples est conservé un petit fichier relié dans lequel sont consignés les regestes de documents qui devaient composer les archives épiscopales de Squillace au XVIII e siècle: il y a 53 parchemins allant du $\mathrm{XI}^{e}$ au XV $\mathrm{XV}^{e}$ siècle concernant les droits de l'évêque sur le village fortifié d'Alano et d'autres territoires du diocèse ${ }^{88}$. Enfin l'existence d'une cour ecclésiastique diocésaine, qui a été soutenue par le baiulus du souverain, est rapportée dans une source de l'époque monarchique ${ }^{89}$; nous ne savons pas s'il s'agissait d'une prérogative déjà existante à l'époque comtale, mais souvent, l'évêque disposait canoniquement de droits ex officio et ratione personae, ce qui lui permettait de juger les clercs et les prêtres grecs du diocèse; ratione rei il avait également le droit de punir certains crimes moraux tels que l'adultère et la sorcellerie, mais la juridiction épiscopale ne faisait pas double emploi avec celle des autorités civiles.

82. Pour ces droits, j'ai établi une liste de tous les archidiocèses et diocèses de la région dans ma thèse de doctorat (BERARDI, 2017a). Sur les dîmes, qui en Calabre ont pesé sur les droits publics de tout le diocèse, parfois seulement sur la ville épiscopale, sur les juifs et sur certains monastères peu importants situés dans le district ecclésiastique voir Decimae. Il sostegno economico dei sovrani alla Chiesa del Mezzogiorno nel XIII secolo, K. Tоомаspoeg (éd.), p. 321-382.

83. Par exemple, un $\sigma \iota \gamma$ i $\lambda \lambda_{\iota}$ ov de Roger ${ }^{\text {er }}$ de 1086, qui a fait don de terres à Arnolf évêque de Mileto, ainsi que de droits de pâturage, de bois, de 95 hommes, de dîmes, et a donné l'autorisation de construire des moulins et d'administrer la justice, mais le texte est conservé uniquement dans une transcription tardive en latin qui semble ne pas être authentique - bien que la source se réfère probablement à un $\sigma ı \gamma^{\prime} \lambda \lambda_{\iota} \mathrm{v}$ authentique dans lequel tous ces droits publics n'étaient probablement pas indiqués. Voir la dernière édition Documenti greci e latini..., doc. 10.

84. Voir des exemples dans Peters-Custot, 2014a, p. 189 sq.

85. Dernière édition Documenti greci e latini..., J. BECKER (éd.), doc. 30, 41

86. Ferdinando Ughelli, Italia Sacra, IX, coll. 425-426.

87. Peters-Custot, 2014 a, p. 67.

88. Regia Camera della Sommaria, Dipendenze della Sommaria - II serie, Economi regi, 38/1 Privilegi e istrumenti relativi alla mensa vescovile di Squillace.

89. Ferdinando UghelLI, Italia Sacra, IX, coll. 431-433. 
Nous avons vu que la politique monastique normande suivait deux directions: le monachisme latin (bénédictin) et le monachisme grec ${ }^{90}$. Le pouvoir public a créé des monastères bénédictins surtout au centre-sud de la région, comme S. Maria della Matina, la SS. Trinità de Sant'Eufemia ${ }^{91}$, la SS. Trinità de Mileto et enfin la collégiale de S. Maria à Bagnara Calabra. Presque tous les monastères avaient des possessions limitées, à l'exception, dans la Calabre comtale, de S. Maria della Torre, la SS. Trinità de Mileto et S. Maria de Bagnara, qui possédaient des propriétés dispersées. Pour la SS. Trinità di Mileto la documentation normande, publiée par Léon-Robert Ménager ${ }^{92}$, nous montre une seigneurie imposante pour le contrôle des hommes et des casalia, cependant certains documents concernant des droits banaux semblent interpolés. Par exemple, il nous est parvenu un diplôme comtal de 1091 selon lequel le droit public de construire des moulins sur ses territoires était offert à l'abbaye, qui pouvait utiliser les eaux publiques sans taxes, collecter les dîmes des monastères grecs et latins situés dans les territoires de l'abbaye et organiser deux foires annuelles devant le monastère ${ }^{93}$. En fait il s'agit d'interpolations postérieures, car, malgré l'importance de l'abbaye de Mileto à cette époque, les droits auraient été ceux d'une seigneurie banale, ce qui est très peu probable à cette époque dans la région ${ }^{94}$.

Une autre seigneurie fondamentale est celle qui est née avec les ermites de San Bruno, seigneurie bien présente jusqu'au XVI ${ }^{e}$ siècle ${ }^{95}$. Annick PetersCustot a montré qu'il ne s'agissait pas d'une chartreuse, mais d'un monastère géré selon les normes bénédictines. De plus, la chercheuse a analysé de façon neuve toutes les sources disponibles sur cet important monastère de l'époque normanno-souabe ${ }^{96}$.

Enfin, sur la collégiale de S. Maria de Bagnara Calabra, il convient de noter qu'en raison de son emplacement, un port florissant a été construit à Bagnara: pour cette raison, l'exemption du ius lignaminum est mentionnée dans certains de ses documents ${ }^{97}$. Nous ferons observer que de nombreux documents

90. Panarelli, 2005; Panarelli, 2006; Peters-Custot, 2009a, p. 266 sq. Sur le monachisme bénédictin, voir l'article récent d'Umberto Longo (LoNGO, 2020)

91. Sur ces deux monastères voir BERARDI, 2017a, chapitre II : La peculiarità della signoria calabrese: il periodo pre-monarchico.

92. MénAger, 1958-1959. Celles des époques souabe et angevine, non publiées, sont conservées au Collège grec de Rome. Je travaille actuellement sur la transcription de ces sources.

93. MÉnAger, 1958-59, doc. 7.

94. À l'époque monarchique, le monastère a perdu lentement son importance, notamment parce que Palerme est devenu le nouveau centre.

95. Voir l'édition de la Platea de 1530, dans La Platea di S. Stefano del Bosco, P. De Leo (éd.). Pour l'analyse socio-économique de ce document voir SALERno, 2006, p. 31 sq.; SALERno, sous presse (je remercie Mariarosaria Salerno [Université de Calabre] de m'avoir permis de lire cet article avant sa publication).

96. Peters-Custot, 2014a, p. 103 sq. Voir aussi Peters-Custot, 2018b, p. 219-239.

97. Annliese Nef mentionne (dans NeF, 2010, p. 148 et 155), dans la Sicile islamique, une corvée consistant à fournir du bois, qui correspond certainement au ius lignaminum. À ce stade, on peut supposer qu'il s'agit d'un héritage du service militaire byzantin datant au moins du IX ${ }^{\mathrm{e}}$ siècle, et exigé à la fois en Calabre et en Sicile. 
concernant cette collégiale calabraise ont été préservés et sont conservés aux Archives de Saint-Jean de Latran ${ }^{98}$.

En ce qui concerne le monachisme grec, la situation est assez inégale, bien que son maintien ait certainement contribué à la paix sociale. Après la conquête normande, certains monastères grecs ont disparu, d'autres ont été cédés aux nouveaux monastères latins, d'autres encore sont restés indépendants. Le système byzantin du métoque ( $\mu \varepsilon t o ́ \chi ı v)$ montre que ce n'était pas une spécificité latine de confier des monastères à de plus grandes abbayes, l'affiliation était une question purement économique et, pour la préservation du monachisme grec, les fondations postérieures de S. Maria del Patir et de l'archimandritat de Messine sont emblématiques ${ }^{99}$.

Les plus riches monastères grecs étaient $S$. Giovanni Théristès ${ }^{100}, S$. Filippo de Gerace ${ }^{101}$ et S. Bartolomeo de Trigona ${ }^{102}$. Les nombreuses fondations nouvelles, souvent liées à la dynastie des Hauteville, bénéficiaient d'exemptions sur leurs terres et leurs hommes: des prestations de travail, des services et des contributions liés à l'utilisation gratuite des forêts et des pâturages (herbaticum, escaticum, glandaticum). Accessoirement sont signalées des exemptions d'angaria et de taxes pour de nombreux paysans dépendants, qui n'étaient toutefois pas toujours dispensés des prestations publiques; certains monastères jouissaient aussi de l'exemption du plateaticum mais presque tous les dossiers de ces monastères ont été faussés et interpolés dans les périodes où le pouvoir public était faible ${ }^{103}$.

Les institutions ecclésiastiques (monastères et cathédrales) ont probablement aidé - avec les agents publics et pour le libre usage des droits publics - le Grand Comte à protéger les biens du «demanium» public contre les aristocrates.

\section{Le phénomène du vilainage}

Un autre aspect fondamental de la seigneurie laïque et ecclésiastique calabraise - surtout en comparaison avec d'autres régions de l'Italie méridionale - était l'importance des concessions de dépendants. Nous avons dit qu'il y avait des

98. Ceci est un cas particulier, car cette documentation, qui couvre la période $\mathrm{XI}^{\mathrm{e}}-\mathrm{XV}^{\mathrm{e}}$ siècle, semble globalement authentique. Dans une source angevine de Robert d'Anjou (1309) - publiée en annexe (doc. 10) dans BerARdi, 2017a - il est indiqué que les Normands ont donné la dîme sur les prises de la marine de Bagnara, que ce soit par les dépendants du monastère ou par d'autres pêcheurs. Cette dîme n'est pas signalée par les sources que nous avons gardées concernant la période normande; il s'agira probablement d'un deperditum ou d'une concession survenue plus tard, mais remontée par interpolations jusqu'au début de la période normande. Voir aussi les Archives de Saint-Jean de Latran, Q. 3. I. 20.

99. Peters-Custot, 2009a, p. 289-306; voir aussi Peters-Custot, 2018b, p. 219-239.

100. Saint-Jean Théristès (1054-1264), G. Mercati, C. Giannelli et A. Guillou (éd.).

101. SCHNEIDER, 1907.

102. Falkenhausen, 1999; Berardi, 2015b.

103. De plus, même les réserves agricoles ou hameaux, même s'ils étaient offerts, n'étaient pas automatiquement exemptés de taxes et de prélèvements, d'où la mention spécifique, parfois falsifiée, de l'exonération. Le plus important résumé sur la seigneurie monastique du sud de l'Italie est dans MARTIN, 2008. 


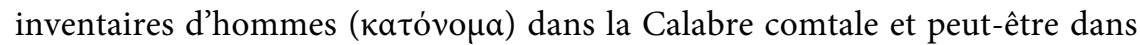
le nord, mais il faut bien rappeler que le fait de figurer dans un inventaire ne signifiait pas ne pas être libre ou ne pas être en mesure de posséder des biens: aussi bien les paysans propriétaires que leurs dépendants appartenaient à l'autorité comtale - ils n'étaient donc pas sous la domination complète des aristocrates ou des institutions religieuses - et pouvaient donc être enregistrés avec des notaires, des moines et des prêtres grecs ${ }^{104}$. De plus, on peut supposer que l'utilité principale de ces listes d'hommes était de sauvegarder les droits $\mathrm{du}$ souverain sur ceux qui n'y figuraient pas; en outre, leur «dépendance» se manifestait avant tout en cas d'absence d'héritiers naturels et, finalement, le phénomène du vilainage aurait conduit, petit à petit dans les siècles suivants, vers une dépendance personnelle.

Les différentes catégories (avec leur terminologie spécifique) des hommes qui ont été examinés dans les inventaires et les donations étaient d'abord en grec

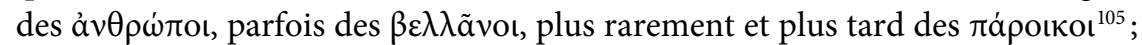
la concession d'hommes a permis au pouvoir public de promouvoir la mise en valeur agricole des terres sous la protection des monastères et des fidèles laïcs, mais la libre propriété, petite et moyenne, a persisté ${ }^{106}$.

Malgré les différences des droits et de l'autorité militaire entre les seigneurs laïcs et ecclésiastiques, nous pouvons dire que les églises et les monastères ont été intégrés dans le système et ont contribué efficacement au maintien de la paix avec les communautés locales.

\section{La Calabre méridionale dans le Regnum Siciliae}

La constitution de la monarchie, en 1130, a eu un impact significatif sur la consolidation des institutions; j'ai prouvé que la Calabre - probablement avec la Sicile - avait été utilisée par Roger II comme modèle pour la structure des autres régions du royaume ${ }^{107}$.

La source la plus importante de la période - bien qu'elle ne se réfère pas au territoire de notre étude mais peut être comparée aux documents calabrais - est le Catalogus baronum, une liste d'aristocrates et d'institutions religieuses des

104. Peters-Custot, 2017 a.

105. Sur cette terminologie voir PATLAgEAN, 2008 et BerARd, 2017a où j'ai résumé toute la question de la paysannerie calabraise ainsi que la terminologie spécifique des corvées. Pour les parèques byzantins étudiés par Annick Peters-Custot avec les paysans normands, il convient de noter que dans un cas seulement, ils ont été signalés dans la Calabre comtale (MÉNAGER, 1957, doc. 3), les autres exemples sont tous du nord de la région (BERARDI, 2017a, p. 61 sq.). On peut supposer que le mot latin colonus - issu de la tradition latine de l'Antiquité (PATLAgEAN, 2008, p. 532) - est, dans le contexte de la Calabre, la traduction latine du terme byzantin paroikos; de même pour le mot rusticus, mais il faut préciser que tous les exemples viennent de la Calabre ducale. Voir BERARDI, 2017a, chapitre II: La peculiarità della signoria calabrese: il periodo pre-monarchico.

106. Pour plus d'informations sur le phénomène du vilainage de l'Italie méridionale et les travaux agricoles voir: Martin, 1987; CArocCi, 2009, p. 205-241; Peters-Custot, 2009b; Carocci, 2014, chapitre 12; CAROCCI et LORÉ, 2017; LOUD, 2018.

107. BerARd, 2017a, chapitre III: La peculiarità della signoria calabrese: il periodo monarchico. 
régions du nord du royaume qui possédaient des «fiefs» et des propriétés pour lesquels ils devaient un service militaire ${ }^{108}$. Il y a un débat sur la nature de ces biens recensés: Sandro Carocci - contrairement à l'historiographie classique estime que le terme de feudum se rapportait alors à la pleine propriété chez les personnages les plus importants du royaume, lesquels avaient des obligations militaires sans contraintes légales, et que ce n'est qu'à l'époque souabe que la féodalité devint un système complet dans le royaume de Sicile ${ }^{109}$. Le terme feudum militis n'est pas conçu - continue à juste titre Sandro Carocci - comme une indication de la nature féodale d'une possession, mais uniquement comme une unité de mesure du service militaire; tenet de, pour sa part, n'atteste pas de la concession féodale d'un bien, mais simplement de l'existence d'un lien de subordination, parfois vraiment féodal, d'autres fois uniquement militaire ou territorial ${ }^{110}$. D'autre part, Sandro Carocci lui-même rappelle que beaucoup possédaient déjà des biens féodaux à l'époque de Roger II ${ }^{111}$. En vertu de cette opinion ${ }^{112}$, une question pourrait être posée: en Calabre, beaucoup

108. Jamison, 1971; Catalogus baronum, E. Jamison; Catalogus baronum. Commentario, E. Cuozzo (éd.); CARocci, 2014, p. 135 sq.

109. Carocci, 2014, p. 127 sq.

110. Ibid., p. 131.

111. Ibid., p. 139 et passim.

112. Sandro Carocci définit le Catalogus comme un projet féodal qui ne peut être considéré comme la photographie fidèle de la réalité (CARocci, 2014, p. 139), niant que l'inventaire indique la nature féodale ou allodiale des biens enregistrés (CAROCCI, 2014, p. 138-142). Toutefois, je pense que, en dépit de la terminologie féodale encore instable à l'époque monarchique normande comme l'a justement démontré Sandro Carocci, il faut reconnaître qu'il y avait peut-être une distinction dans le Catalogus entre propriété féodale et propriété non féodale au moins pour les seigneuries ecclésiastiques. Déjà Evelyn Jamison (JAMISON, 1971) a expliqué comment, dans le Catalogus baronum, étaient répertoriés des fiefs et d'autres propriétés, en particulier celles des seigneuries monastiques (voir aussi MARTIN, 2008, p. 198-201), mais aussi les seigneuries épiscopales détiennent des fiefs (voir par exemple Catalogus baronum, E. JAMIson, $\$ 107,402$, 1221-1222 ; Loud, 2007, chapitre 6). Par exemple l'abbaye de S. Giovanni in Venere dans les Abruzzes (Catalogus baronum, E. JAMIson, $\$ 1204-1215$ ) est tenue d'envoyer des chevaliers pour le service militaire au titre de ses possessions «féodales» (tenet feudum). On retrouve la même situation pour les autres monastères des Abruzzes tels que S. Clemente a Casauria $(\$ 1217)$ et S. Stefano ad Rivum Maris ( $\$ 1218-1220)$. Hors des Abruzzes, les «fiefs monastiques» apparaissent seulement pour S. Marie de Banzi (en Basilicate, $\$ 87$ ) et S. Maria de Grottaferrata à Rofrano (Salerne, \$ 492). L'administration elle-même distingue les situations dans le cas du Mont-Cassin $(\$ 823)$ qui offre (obtulit) pour la magna expeditio des chevaliers au titre probablement de ses «tenimenta», la même situation s'applique à l'abbaye de la Trinité de Venosa (obtulit pro tota terra et tenimento suo, $\$ 408$ ). On ne saurait expliquer ces situations exceptionnelles, une erreur de l'administration monarchique? Pourquoi cette distinction, il y avait peut-être une distinction de propriété ? Pourquoi l'administration a-t-elle tendance à exiger le service militaire des monastères "propriétaires de fiefs» alors que le Mont-Cassin et la Trinité de Venosa pouvaient l'offrir pour la possession de leur terre? Est-ce que, déjà à cette époque, l'administration monarchique - en vertu du modèle siculo-calabrais - avait tendance à distinguer les fiefs et la propriété ? En conclusion, si on excepte le cas particulier de la magna expeditio ou d'autres campagnes militaires, seuls les aristocrates devaient des chevaliers au souverain pour leurs «fiefs", mais il est normal que dans ces cas exceptionnels les «propriétés allodiales» soient également incluses dans ces enregistrements. Je remercie Jean-Marie Martin (CNRS) d'avoir signalé le "problème des seigneuries ecclésiastiques» dans le Catalogus baronum et pour les nombreux conseils qu'il m'a donnés pour chaque partie de cet article. 
possédaient-ils déjà des concessions «féodales» pour lesquelles le service militaire devait être effectué, principalement à cause de l'armée qui a servi à Roger II pour consolider son pouvoir dans le reste du continent entre 1127 et 1143 ? Est-ce durant cette période que le service militaire a été imposé - exceptionnellement - sur les biens allodiaux ${ }^{113}$ ? Cependant, comme nous le verrons, il semble que, même à l'époque monarchique, il n'y ait presque pas de différence - du point de vue de la prestation du service militaire pour les terres concédées - entre un fief, un tenimentum et un casale: parfois tous sont classés pour le service militaire par l'unité de mesure du feudum militis. Mais il est probable que les propriétaires de tenimenta et casalia soient exceptionnellement taxés - avec une valeur inférieure par rapport à un fief - pour le service militaire uniquement en vue d'une prochaine campagne militaire.

Nous avons au moins deux exemples de concessions «féodales» dans la région durant la période rogérienne, à Oppido et à Bisignano. Pour Oppido il s'agit d'un document de $1188^{114}$ dans lequel est rapporté un acte de 1138 , écrit sur un papier de coton arabe enregistré dans les bureaux de Palerme ${ }^{115}$ : Maximilia, dame d'Oppido et sœur du roi Roger ${ }^{116}$, a fait don d'un feudum (feudum

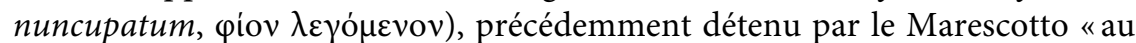
temps du marquis ${ }^{117}$, à Guillaume de Brui. Le píov était composé de vignes, de

113. L'importance de l'application du modèle siculo-calabrais dans le reste du Royaume par Roger II a également été signalée par Sandro Carocci (CAROCCI, 2014, p. 114).

114. Syllabus graecarum membranarum..., F. Trinchera (éd.), doc. 225: le maitre justicier Jean de Reggio s'est rendu à Oppido à la demande du roi Guillaume II avec d'autres «barons», le seigneur de Bovalino, Guillaume de Gerace et le justicier - même s'il n'a pas ce titre - Hugues de Reggio, pour investir le dominus Asclettin du fief ayant appartenu à son père, Guillaume de Brui. Cependant, Asclettin a rencontré l'opposition de la dame d'Oppido, Hodierna et de ses frères Bohémond et Jean. Ceux-ci affirmaient que seule une partie des biens et des hommes énumérés dans le document de 1138 présenté par Asclettin faisaient partie du fief de son père, proposant ainsi une liste plus restreinte de biens (vignobles, cultures et terres agricoles) et d'hommes (äv $\theta \rho \omega \pi \mathrm{o}$ de Bovalino). L'étendue réelle du fief a été renvoyée au témoignage des anciens de la terre, qui n'ont répertorié que neuf familles de vilains et des biens réduits par rapport au document de 1138 déjà analysé dans le texte ci-dessus (voir aussi CArocCI, 2014, p. 259, n. 130, p. 262-263). Dans Rome, Biblioteca Angelica, G. B. Prignano, Historia delle famiglie di Salerno normanne, ms. 276, $\mathrm{f}^{\circ} 357 \mathrm{r}$., il est rapporté qu'en 1168 un certain Roger était seigneur d'Oppido en Calabria Ultra, mais il pourrait s'agir d'une erreur de Prignano puisqu'il existe d'autres centres nommés Oppido en Campanie et en Basilicate.

115. Il est certain que la duana de secretis, office royal fondé vers 1140 et dont dépendaient la Calabre et la Sicile (NeF, 2011, p. 251 sq.), avait établi des registres - maintenant perdus - concernant les seigneurs calabrais et siciliens, peut-être plus précis que le Catalogus baronum même.

116. Falkenhausen, 2001, p. 361-377.

117. C'est certainement Eudes le Bon Marquis (supra), de la lignée des seigneurs de Monferrato, la famille aléramique d'Adélaïde de Vasto (à propos de cette famille en Italie méridionale, voir GARUFI, 1910). Les sources sur la dynastie de cet aristocrate sont assez discordantes, car il semble avoir été marié deux fois. Lors du premier mariage, il a épousé Emma, sœur ou fille - selon Raoul de Caen - de Robert Guiscard. De leur union sont nés Tancrède et Guillaume, le premier (1076-1112), à qui fut dédié le De rebus gestis Tancredi principis de Raoul de Caen, fut l'un des protagonistes de la Première Croisade: prince de Galilée, régent d'Antioche et, à la mort de Bohémond, prince d'Antioche; le second qui a participé à la croisade est mort en Terre Sainte (Radulphi Cadomensis, Tancredus, E. D’Angelo [éd.], p. XI, 6. Voir aussi Russo, 2002; Salerno, 2016, p. 55-65). Sa seconde épouse, Sikelgaite, et son fils Pierre ont également 
praedia, de châtaigniers, de maisons et de 32 familles de paysans qui devaient

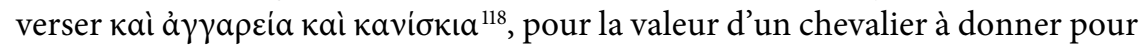
l'armée royale ${ }^{119}$.

L'exemple de Simeri peut être relié au document d'Oppido: une bonne partie du territoire a été donnée par Roger II à un de ses fidèles du nom de Deutesalve et à sa famille en $1144^{120}$. C'est une source très importante pour la seigneurie calabraise, qui nous est parvenue dans une traduction latine faite en 1231 d'un acte grec de la chancellerie de Frédéric II, transmise à son tour par un registre angevin de 1315. Le roi a accordé à Deutesalve des propriétés à Simeri appelées tenimenta, dont la consistance est décrite en détail: 50 hommes avec leurs descendants, qui devaient payer pour le pâturage d'herbivores et de porcs, des amendes judiciaires et ce qu'il était habituel de payer ${ }^{121}$; le droit de recevoir sur ces territoires des extranei ${ }^{122}$ "qui ne sont pas enregistrés dans nos quaterniones»; ont également été accordés le tenimentum de Pilatta avec une cultura, trois moulins sur la rivière Simeri et d'autres terres, quatre fermes avec plena et perfecta potestas, enfin l'utilisation de l'eau pour les moulins. En contrepartie, l'aristocrate in capite de domino rege devait effectuer personnellement le service militaire d'un mois à ses frais si les opérations avaient lieu en Calabre. En outre, il était responsable de ce service dans la seigneurie et dans les parties concédées de ses tenimenta - différence décrite abondamment dans le Catalogus baronum, où les biens directs du noble étaient définis comme in demanio, tandis que ceux donnés à un de ses subordonnés étaient in servitio -, et si les opérations avaient lieu en dehors de la région et pendant plus d'un mois il devait recevoir de la Curia un stipendium. De plus, Deutesalve devait rester dépendant du roi même si le territoire où se trouvaient les biens et les hommes qui lui étaient assignés était concédé en seigneurie à un autre aristocrate ${ }^{123}$. Cette source a été jugée peu sûre par V. von Falkenhausen ${ }^{124}$ sur la base d'interpolations ou d'interventions possibles du traducteur, mais à mon avis, elle est authentique. Bien sûr, la traduction du grec en latin par le fonctionnaire de Frédéric II n'est pas la meilleure, mais il serait insensé de falsifier une source pour laquelle un tel

conservé le titre de marquis - n'appartenant clairement pas aux hiérarchies du Mezzogiorno normand - après sa mort. Voir supra note 61,62 .

118. Sur ce type de corvées, voir MarTin, 2001, p. 509. Dans la source, d'autres phia sont mentionnés qui bordent celui de Guillaume de Brui.

119. Indiqué dans la source de 1188: "meus enim pater possedit feudum unius militis». Voir aussi CARocCI, 2014, p. 259. Je remercie S. Carocci (Université de Rome «Tor Vergata») pour son aide dans l'interprétation de cette importante source.

120. Kenr, Karl Andreas, Die Urkunden der normannisch-sicilischen Könige: eine diplomatische Untersuchung, doc. 53.

121. Roger II a précisé que tous les hommes du royaume étaient soumis à leurs seigneurs même dans le iudicamentum.

122. Sur cette figure Falkenhausen, 2012.

123. Comme l'a bien montré Sandro Carocci, il existe un parallélisme avec la forme angevine des concessions féodales, qui atteste qu'il était très courant qu'à l'intérieur d'un territoire castral, il y ait des biens d'autres aristocrates. Voir CAROCCI, 2014, p. 451-452.

124. Falkenhausen, 2013, p. 59. Du même avis Sandro Carocci, dans Carocci, 2014, p. 249, n. 84. 
service est dû au souverain; de plus les biens et les droits - en principe - sont assez importants pour constituer un «fief» ou une propriété pour laquelle le service militaire était dû en Calabre. En outre, grâce à ce document on peut conclure qu'un tenimentum (bien-fonds détenu par un aristocrate petit ou moyen) pourrait avoir la même fonction de contrepartie au service militaire exigé des aristocrates qui avaient un fief, ce qui pourrait expliquer la grande absence de la terminologie féodale de l'époque ${ }^{125}$. On peut également supposer que les biens détenus par Deutesalve à Simeri étaient burgensatica (c'est-à-dire non féodaux, propriété foncière libre). En fait, bien que les biens féodaux et les biens burgensatica soient de natures différentes, le service militaire des aristocrates était parfois taxé sur ce type de biens. Cette source démontre aussi ultérieurement l'existence d'un service militaire dans le sud de la Calabre - mais, je pense, aussi dans le nord - déjà avant l'établissement du Catalogus baronum, et confirme que dans la région le «contrôle» d’hommes dans les propriétés seigneuriales et «féodales» était fondamental, comme pour le piov de Guillaume de Brui. D’autre part, le contrôle des hommes était également important dans d'autres types de concessions où le service militaire n'était pas dûu $\hat{u}^{126}$.

J'ai également constaté que les fiefs calabrais étaient de petite taille et ils ont été inclus dans les territoires du demanium, ou dans les autres seigneuries appelées baronie au moins à l'époque souabe. Cette baronia était généralement composée d'un castrum avec les hommes et casalia sur lesquels le seigneur pouvait lever des taxes et des droits de basse justice et donc, pas toujours de fiefs ${ }^{127}$. Parfois, un fief ne consistait qu'en une vigne ou des dépendants, mais pour la période monarchique normande, le vocabulaire reste imprécis, les comtes

125. Pour un autre exemple où le service militaire est imposé à un tenimentum voir Le pergamene dell'archivio vescovile di Caiazzo (1007-1265), S. CATEllo et al., p. 240-244 (1184). On trouve également un document non daté, mais clairement rédigé sous le règne de Roger II, dans lequel le service militaire a été demandé à Gervais Ruffus pour des tenimenta près de Sciacca, en échange il a dû fournir un arbalétrier à pied pendant un mois en Sicile (voir BresC, 2002, p. 89). Sandro Carocci a également souligné que la monarchie, à partir du milieu du XII ${ }^{\mathrm{e}}$ siècle, a cherché à imposer le caractère militaire de toute possession des élites laïques. Voir CAROCCI, 2014, p. 141.

126. Voir par exemple I documenti inediti..., C. A. GARUfI, doc. 7 (1127), dans lequel Roger II a accordé à Ansaldus, vicomte d'Arri, le casal Nàsari (en Sicile) avec 32 vilains musulmans, un moulin, des vignes et des terres sans demander le service militaire. Peut-être parce que c'était son fonctionnaire?

127. Documenté dans des sources souabes qui reflètent sûrement des documents de la période normande et dans des documents angevins reprenant des sources de la période souabe. Voir surtout les enquêtes ordonnées par Charles I I' d'Anjou (I Fascicoli della Cancelleria Angioina ricostruiti dagli Archivisti napoletani, S. PAlmieri [éd.], p. 33 sq., p. 57 sq., p. 185 sq., mais en particulier p. 299 sq.). Pour la période normande nous avons un autre exemple: à Stilo, considéré comme territoire domanial, en 1176 un píov devant le service militaire de quatre chevaliers appartenait à un certain Hugues, fils de Matthieu Sabuti, qui pour son théorètron a donné le tiers du piov susmentionné à une Maleinos - famille italo-grecque connue - nommée Regalia. La mère de la mariée - épouse de Nicolas Maleinos - a reçu en dot plus de 4000 tarins (Syllabus graecarum membranarum..., F. Trinchera [éd.], doc. 187). Cela montre que même détenir un tiers de ce fief présentait un certain avantage économique. Pour d'autres exemples de fiefs en Calabre, voir BERARDI, 2017a, chapitre III : La peculiarità della signoria calabrese: il periodo monarchico: déjà à l'époque de Tancrède (1189-1193), Henri VI (1194-1197) et Constance de Hauteville (1197-1198) dans la région la terminologie «féodale» est bien documentée. 
les plus importants n'étaient jamais mentionnés comme possesseurs d'un feudum - contrairement à l'époque souabe ${ }^{128}$.

À cet égard, l'exemple de Bisignano semble important ${ }^{129}$ : en 1248 , les reintegratores feudorum affirmèrent que, dans ce territoire, il y avait de très petits fiefs, parfois même assimilables à un centième de chevalier; les propriétaires possédaient également des biens burgensatica qu'il était impossible de distinguer des res feudales accordées par Roger II à travers son sigillia. Cette situation pourrait être comparée à quelques petits fiefs taxés de moins d'un chevalier et décrits par le Catalogus baronum dans le Salento - une région assez proche de la Calabre et ayant une tradition similaire - et déjà comparée par Jean-Marie Martin à propos du service militaire des franci de San Lucido, rapporté dans la Platea de l'archevêque de Cosenza, des franci qui avaient pour tâche la surveillance militaire de la côte ${ }^{130}$. Le contexte et la raison de la constitution de ces petits fiefs pourraient être très similaires, car Bisignano n'est pas loin de San Lucido. Il est possible de faire une autre comparaison indirecte - car elle a eu une évolution différente - avec la milice napolitaine à laquelle ont été attribués des fiefs petits ou très petits ${ }^{131}$. Il s'agissait donc de personnes riches - à la fois à Bisignano et à Naples - à qui le souverain, pour obtenir le «service militaire permanent", n'accordait que de petits ou très petits fiefs.

L'autre partie de la source souabe est également importante: les responsables ont constaté, consternés, que les fiefs accordés par Roger II et décrits dans ses sigillia ne mentionnaient souvent pas de terre ni de propriété foncière, mais uniquement des hommes et des moulins, sans parcelles ${ }^{132}$. À partir de cette déclaration, nous pouvons élaborer quelques considérations: le rédacteur a probablement été frappé par la présence de listes de paysans dans les fiefs plutôt que par la taille de ceux-ci, à la différence des fiefs du nord du royaume. En ce qui concerne les moulins, peut-être y avait-il confusion du responsable souabe; ou cela pourrait prouver que, malgré tout, la possession de certains moulins pouvait garantir le service militaire ${ }^{133}$. Sur la consistance des fiefs, on peut supposer qu'ils étaient si petits qu'ils n'étaient pas composés de terres; comme en témoignent les agents de Frédéric II, d'autre part en Calabre, les pratiques en matière d'héritage (selon la loi lombarde) étaient appliquées à la fois aux biens féodaux et aux burgensatica, ce qui entraînait une forte fragmentation des seigneuries; ce qui était recherché

128. I Fascicoli..., S. Palmieri (éd.), p. 306-307. Cependant en 1184 le vice-chancelier du royaume Matthieu d'Aiello détient un fief (dernière édition de la source dans Documenti dell'Eremo della Torre e del monastero di Santo Stefano del Bosco [secc. XI-XIII], F. IANTorno [éd.], doc. 84). Matthieu d'Aiello fut vice-chancelier de 1169 jusqu'à la mort de Guillaume II. Voir Panarelli, 2008. Les comtes n'ont-ils pas de fiefs simplement parce que nous n'avons pas conservé les sources?

129. Acta Imperii inedita saeculi XIII et XIV, E. Winkelmann, doc. 927.

130. Martin, 2007; Martin, 2012. Pour la Platea, voir La Platea di Luca..., E. Cuozzo (éd.).

131. Sur la milice napolitaine voir MARTIN, 2005, p. 23 sq.

132. Voir aussi un acte de Gerace de 1192 - mais qui se fonde sur une source plus ancienne - selon lequel au fils de Giulli de Amato sont confirmés par le roi Tancrède un moulin et une terre de 100 salmes. En retour, il devait le service militaire d'un chevalier à la cour royale. Voir Tancredi et Willelmi III regum diplomata, H. ZielinsKi (éd.), doc. 28.

133. Supra note précédente. 
par Roger II mais aussi par d'autres souverains ${ }^{134}$. En bref, les suppositions sont assez nombreuses ${ }^{135}$, mais il est indiscutable que, en Calabre, les domaines nobles pour le service militaire reposaient - comme déjà dit - davantage sur la possession de personnes que sur celle de territoires; naturellement, la dépendance et le prélèvement sur les paysans variaient selon les conditions juridiques, même si le píov ou tenimentum appartenait à un seigneur de castrum ou à un chevalier. Le pouvoir territorial de la seigneurie, même dans les siècles suivants, est resté une réalité dans l'Italie méridionale ${ }^{136}$, toutefois il semble que les seigneuries majeures se sont développées dans le centre-sud de la Calabre par rapport au nord ducal.

En Sicile, nous trouvons également un document intéressant: en 1162 Jean Malcovenant a demandé et obtenu du roi Guillaume Ir $^{\text {er }}$ le transfert du château de Calatrasi pour lequel il n'était pas en mesure de fournir onze milites, en échange, il a reçu deux casalia valant au total feudum trium militum ${ }^{137}$. Peut-être la monarchie a-t-elle tenté de donner de plus grands territoires pour obtenir plus de chevaliers, mais l'aristocratie ne semble pas avoir les ressources nécessaires pour suivre cette évolution. Ce document démontre également que les casalia étaient parfois déjà tarifés pour le service militaire à l'époque normande.

Qu'est-ce qui pourrait être considéré comme un feudum militis à l'époque normande? En Sicile, les reintegratores de Frédéric II ont déclaré comment le fief s'est formé sur un modèle qui devrait correspondre au fief d'un chevalier, ou à une terre de 30 charruées de 30 salmes, dont 10 conservées en demanium et 20 cultivées par des vilains ${ }^{138}$.

Toutefois, Sandro Carocci a démontré «que, selon le jugement de la bureaucratie royale, un vrai feudum militis correspondait à la possession d'une bonne trentaine de vilains ${ }^{139}$. En revanche, toujours le même Sandro Carocci a souligné qu'il s'agissait d'un seuil théorique et que le feudum militis était une unité de mesure variable ${ }^{140}$.

134. Dans une enquête angevine ordonnée par Charles $I^{\mathrm{er}}$, il est précisé que, près de Bisignano, les successions féodales ont été réalisées dans le respect de la loi lombarde (I Fascicoli..., S. PALMIERI [éd.], p. 37); par conséquent, il est également possible que les cadets de petites familles aristocratiques aient fourni une partie des chevaliers uniquement avec un moulin, ou que les petits fiefs décrits n'appartiennent qu'aux milites, d'où la description des fonctionnaires. Sur les pratiques successorales en Italie méridionale voir MARTIN, 1998; MARTIN, 2002. Ce type de "morcellement successoral des seigneuries » a été bien étudié pour la France par DÉBAX, 2012, en particulier p. 80-92 (je remercie Didier Panfili [Lamop, Université Paris I] de m’avoir signalé cet important travail).

135. Il est également possible que la confusion des officiers de la période souabe soit simplement due à une manière différente d'enregistrer les hommes / les biens. Après tout, dans la documentation ducale, plus au nord, lorsqu'un don a été fait à des églises et des monastères, des hommes ont été transférés et la référence aux propriétés n’était que générique. Je remercie Vito Loré (Université de Rome 3) pour cette interprétation supplémentaire de la source.

136. Infra.

137. SiragusA, 1885 , p. XXXVIII-XLI.

138. Acta Imperii inedita saeculi XIII et XIV, E. Winkelmann, doc 924.

139. CAROCCI, 2014, p. 261.

140. Ibid., p. 262. Voir surtout pour la Calabre les exemples d'Asclettin de Brui, fils de Guillaume de Brui (supra) qui a dû se contenter de neuf vilains au lieu des 32 détenus par son père dans son

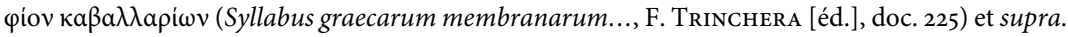


À première vue, il peut sembler que les conditions de la Calabre et de la Sicile, régions dans lesquelles l'exercice des droits de prélèvement et de contrôle sur les familles d'agriculteurs dépendants constituait l'épine dorsale de nombreux patrimoines de quelque taille que ce soit, y compris ceux des milites et des notables locaux, sont assez différentes de celles des régions du nord. Dans le Catalogus baronum, sauf quelques exemples, les fiefs mentionnent quelques paysans. D'autre part, Sandro Carocci a montré que toutes les seigneuries, y compris les possessions des chevaliers, de tout le royaume de Sicile avaient certainement des subordonnés et qu'il est impossible d'affirmer - à travers l'étude du Catalogus baronum - que dans les seigneuries et fiefs du nord, il y avait moins de vilains ${ }^{141}$. Dans tout le royaume, le "contrôle» de paysans est considéré comme une unité de mesure du service militaire.

\section{Construction administrative de la paix monarchique}

Avec la naissance de la monarchie, un important appareil bureaucratique fut créé, dont certains éléments existaient déjà dans le comté de Roger II, comme la duana de secretis, le bureau qui dirigeait le demanium et le secteur financier ${ }^{142}$; les camériers provinciaux sont en revanche documentés en Calabre depuis la période des deux rois Guillaume (1154-1189) ${ }^{143}$. Comme dans le reste du royaume, se constitua en Calabre une forte aristocratie administrative seigneuriale fondée sur la justice et l'armée, qui représentait directement le souverain, ses membres les plus importants étant les cadres recrutés dans le nord de la Calabre parmi les aristocrates les plus fidèles, tandis que dans la partie méridionale du territoire - où un tel groupe existait déjà avant la monarchie - ils étaient surtout italo-grecs. L'autre aristocratie liée à l'armée était composée de connétables, qui avaient un rôle bien défini dans l'organisation de l'armée du roi; dans certains cas apparaitt également le titre de "maitre connétable», qui a autorité sur toute la Calabre ${ }^{144}$.

La plus haute aristocratie seigneuriale - parfois occupée à des charges administratives - était celle des comtes, qui avaient une supériorité militaire sur les autres aristocrates ${ }^{145}$. En Calabre, deux comtés seulement ont été créés: Catanzaro et Squillace. Le comté de Catanzaro fut probablement fondé vers 1140 lorsque Roger II a fait de la seigneurie de la famille de Loritello une circonscription comtale; malgré la révolte de la comtesse Clémence contre Guillaume I ${ }^{\text {er }}$ (1155-1156), son mari Hugues Lupin, comte de Catanzaro, fut peu de temps après magister iustitiarius et comestabulus totius Calabrie, le plus important haut fonctionnaire calabrais, mais la famille disparut avec l'avènement de Henri VI (1194) ${ }^{146}$. Le comté de Squillace a été créé pendant les dernières années du gouvernement de Roger II (1150-1154) pour contrebalancer

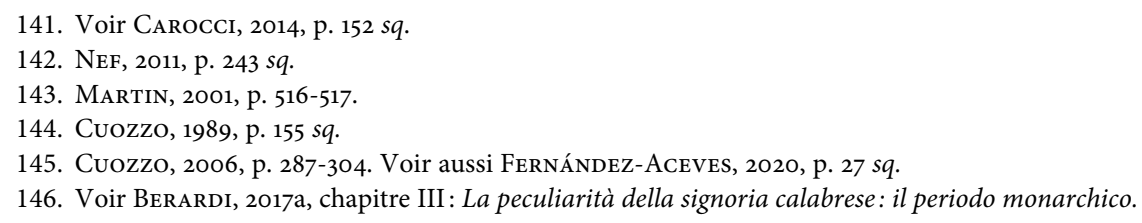


le pouvoir du comte de Catanzaro. Mais le comte de Squillace Evrard participa à la première rébellion des aristocrates contre Guillaume $\mathrm{I}^{\mathrm{er}}(1155-1156)$ et après avoir été vaincu il fut tué, le comté confisqué et concédé au comte Anfusus ${ }^{147}$. Le pouvoir judiciaire des comtes, comme l'ont souligné Jean-Marie Martin et Sandro Carocci ${ }^{148}$, était très limité: il est à peu près certain qu'ils n'avaient pas la haute justice, sauf dans certaines régions du royaume et quand ils détenaient le titre de magister iustitiarius; peut-être Hugues Lupin a-t-il reçu ce titre pour rester au service du souverain et éviter qu'il ne se rebelle.

Les milites ${ }^{149}$, qui sont à cette époque plutôt bien documentés aussi en Calabre, étaient également fondamentaux pour consolider la paix dans le nouveau royaume. Cela prouve que, par rapport à la période pré-monarchique, ils ont acquis un plus grand rôle social, surtout dans la Calabre méridionale d'où ils étaient totalement absents; s'il n'était pas indispensable d'être juge pour devenir chevalier ou vice versa, il y avait probablement un lien ${ }^{150}$, la documentation montre une plus grande cohérence dans les centres appartenant à l'État tels que San Marco et Stilo, peut-être dans le but de mieux contrôler le territoire et bien sûr aussi parce que, comme c'est le souverain qui nomme lui-même les milites, ces derniers lui étaient absolument loyaux ${ }^{151}$. Une particularité de la Calabre méridionale est liée à l'infiltration de certains Italo-grecs, comme les Maleinoi, dans la «classe» aristocratique; toutefois le phénomène est rare et limité à quelques cas, le plus souvent par les femmes: l'aristocratie est restée dans cette période encore «normande» ${ }^{152}$.

Sur leur rôle social, on peut dire qu'au-delà des interprétations des «Assises d'Ariano ${ }^{153}$, c'est avec Roger II que le monde chevaleresque commence à émerger avec des connotations bien précises ${ }^{154}$. En outre, il semble que certaines prérogatives soient communes aux «barons». Les milites ne sauraient être exclus

147. Voir Pseudo Ugo Falcando, De rebus circa Regni Siciliae curiam gestis - Epistola ad Petrum de desolatione Siciliae, E. D’Angelo (éd.), p. 3-12; Peters-Custot, 2012 c.

148. Martin, 1993, p. 799 sq.; Carocci, 2008.

149. Voir la dernière analyse dans CARocci, 2014, p. 133-135, p. 227 sq., p. 251-256.

150. Le fait que des milites occupent des fonctions de juge, de notaire ou de stratège montre que, grâce à la rémunération de ces fonctions, les chevaliers pouvaient effectuer leur service militaire, la plupart d'entre eux n'étant pas riches, même si par ailleurs ils pouvaient bénéficier d'autres biens-fonds et des relations étroites avec des «barons» et des comtes.

151. BerARDI, 2017a, chapitre III: La peculiarità della signoria calabrese: il periodo monarchico.

152. Voir Peters-Custot, 2009a, p. 405 sq. ; Peters-Custot, 2012a, p. 359-374.

153. Pour l'édition, voir Le Assise di Ariano, testo critico, O. Zecchino (éd. et trad.). Il semble être prouvé que l'idée que le roi Roger ait publié les «Assises d'Ariano» est un mythe. La collection survivante des lois de ce roi pourrait bien avoir été publiée sous forme de code au XIII siècle, mais pas à Ariano en 1140 (Houben, 1999, p. 172-188; Loud, 2012, p. 42-44, p. 314-328). Pour la discussion voir CARocci, 2014, p. 132 sq. Pour l'Assise De nova militia liée à la chevalerie normande voir Cuozzo, 1989, p. 23 sq. et Cuozzo, 2008, p. 143 sq.; pour son interprétation à l'époque souabe voir Mineo, 2001, p. 11 et p. 18-19.

154. Cependant il semble que le fait, «les seigneurs étaient nobles parce qu'ils étaient milites", n'a été consolidé qu'à l'époque angevine. À travers l'analyse des Registres de la chancellerie angevine, et pas seulement, j'ai montré que la distinction entre chevaliers et barons a tendance à disparaître, les distinctions de noblesse ne se différenciant que pour le titre comtal; un chevalier était noble et pouvait détenir une baronnie. Voir BERARDI, 2017a, chapitre III : La peculiarità della signoria calabrese: il periodo monarchico. 
de la prééminence, car la possession de chevaux et leur utilisation à la guerre constituaient l'un des visages de la supériorité sociale, en particulier dans la Calabre, qui leur donnait un rôle de premier plan dans la notabilité. En effet, une certaine disponibilité patrimoniale et des paysans subordonnés étaient nécessaires au service militaire, comme Sandro Carocci le prouve également: les chevaliers possédaient des subordonnés sur lesquels ils prélevaient des revenus, mais tous n'étaient pas riches ${ }^{155}$; à mon avis cependant, on pourrait opter - du moins en Calabre où les territoires domaniaux étaient importants - pour la supériorité des chevaliers dans les centres non seigneuriaux ${ }^{156}$.

Comment l'administration locale a-t-elle été utilisée pour consolider le pouvoir monarchique? La baiulatio, la circonscription locale adoptée par la monarchie, les seigneurs et les institutions religieuses, est désormais bien établie; les agents locaux ont tendance à prendre le titre de baiulus, même si les titres de vicomte et de curator ont persisté ${ }^{157}$. Les notaires locaux se recrutaient encore dans l'élite grecque, surtout dans le sud de la Calabre, mais vers 118o, ils commencèrent à perdre du pouvoir; nous avons également noté - comme il a déjà été signalé - que tout au long de la période normande, on ne trouve pas de notables locaux latins, ce qui suggère que pendant la période byzantine, les Grecs dominaient dans toute la région ${ }^{158}$.

Mais la paix monarchique est surtout arrivée - naturellement malgré une certaine opposition - grâce au maintien du pouvoir de l'aristocratie: l'exemple de la Calabre méridionale d'abord, mais aussi de la partie ducale de la «région» pendant la période du duc Guillaume, est emblématique. La nouveauté pour les aristocrates, par rapport à l'époque pré-monarchique, est la relation délicate et souvent conflictuelle avec la monarchie, qui limite encore davantage les pouvoirs judiciaires et banaux des seigneurs, en se posant comme l'intermédiaire incontournable entre les seigneurs et leurs dépendants; en plus des contrôles naturels sur la loyauté politique des aristocrates, le pouvoir royal ajouta - d'après les différentes sources juridiques qui nous sont parvenues, comme les «Assises d'Ariano " - des restrictions sur les droits successoraux et les politiques matrimoniales, notamment avec des taxes sur les fiefs ou les possessions, selon le nombre de chevaliers nécessaires au service militaire ${ }^{159}$.

Une autre limitation apportée par la monarchie à la seigneurie est relative à la territorialité: les seigneurs devaient accepter qu'à l'intérieur de leur circonscription, il y ait des hommes ou des enclaves partiellement ou entièrement exemptés de leur juridiction et dépendant directement du souverain, créant des «trous» et des incohérences territoriales voulues, dans les ensembles fonciers tenus ${ }^{160}$.

155. CAROCCI, 2014, p. 229 sq.

156. BERARDI, 2017a, chapitre III: La peculiarità della signoria calabrese: il periodo monarchico.

157. MARTIN, 1996, p. 113-140.

158. Voir Peters-Custot, 2009, p. 418-19; Peters-Custot, 2012a, p. 359-374.

159. Pour une reconstruction de toutes les familles aristocratiques du sud de la Calabre, voir BERARDI, 2017a, chapitre III : La peculiarità della signoria calabrese: il periodo monarchico.

160. Pour la territorialité de la seigneurie voir CAROCCI, 2006, p. 429 sq. ; CAROCCI, 2014, p. 450-454. Il semble que ce manque de territorialité de la seigneurie ait duré plusieurs siècles, voir SENATORE, 
L'originalité de la Calabre reposait sur la relation entre le souverain (avec son administration publique) et l'aristocratie, qui était sans conditions - malgré quelques exceptions - au service du roi; de ce fait, les nobles régionaux résistèrent assez bien - par rapport à d'autres régions du royaume - aux diverses purges d'aristocrates dans le royaume, de la part des deux Guillaume et d'Henri VI.

Ce schéma resta plus ou moins stable à l'époque de Tancrède (1189-1193), Henri VI (1194-1197) et Constance de Hauteville (1197-1198), et l'administration monarchique continua à fonctionner de manière égale malgré les nombreuses rébellions; c'est peut-être alors que Henri VI ou Constance créèrent les comtés de Tropea et de Montalto. En fin de compte, bien qu'elles aient tendance à se nuancer, il restait des différences entre les deux Calabres, surtout en ce qui concerne l'administration ${ }^{161}$.

\section{Conclusion}

La Calabre comtale se présente comme un territoire particulier dans la transition entre l'état de guerre et l'état de paix des mondes normands. Roger ${ }^{\mathrm{er}}$ a pu y construire une nouvelle société politique dans le contexte très particulier de l'héritage byzantin qui dominait la région à l'arrivée des "Normands". Le Grand Comte a maintenu et, dans un certain sens, consolidé les structures administratives byzantines, revendiquant à la fois la continuité de la domination politique pour le nouveau pouvoir et l'insertion des anciennes élites dans le processus de pacification; d'autre part, il a inséré et adapté dans le contexte de la grande propriété ecclésiastique byzantine le nouveau système seigneurial occidental, lui permettant de mettre en œuvre une reconfiguration politique de la nouvelle aristocratie. La Calabre ducale, considérée par l'historiographie comme une zone d'anarchie similaire aux autres régions du duché des Pouilles, après la mort de Roger Borsa - qui à son tour avait déjà bien contrôlé les aristocraties de la Calabre ducale - a été pacifiée par Roger II, qui déjà pendant le duché de Guillaume avait étendu son contrôle dans le nord de la Calabre.

En ce qui concerne la construction économique et foncière de la domination,

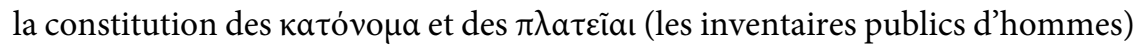
est emblématique: le pouvoir comtal reprend ainsi l'action de recensement et de cadastration propre au pouvoir byzantin. Les Normands dans leur construction politique n'ont pas négligé l'aspect culturel en mettant en œuvre dans la rédaction des documents une politique plurilinguistique gréco-latine, et ont associé les monastères et les cathédrales à la construction politique de la nouvelle société normande.

2010, p. 453; SEnatore, sous presse (Je remercie Francesco Senatore [Université de Naples] de m'avoir permis de lire ce dernier article avant sa publication); BERARDI, sous presse.

161. Pour cette situation en Calabre, voir BERARDI, 2017a, chapitre III : La peculiarità della signoria calabrese: il periodo monarchico. Pour l'aristocratie dans le royaume de Sicile à cette époque, voir Cuozzo, 2004. 
Enfin, la légitimation juridique de la conquête, qui ne pouvait avoir lieu définitivement qu'avec la constitution de la monarchie (1130) et la publication des «Assises d'Ariano" (1140), avait été anticipée dans la Calabre comtale, dès l'époque pré-monarchique: le tribunal de Roger Ir et de Roger II y fut très actif, même si nous n'avons aucune attestation d'un corpus juridique dans la documentation survivante. 


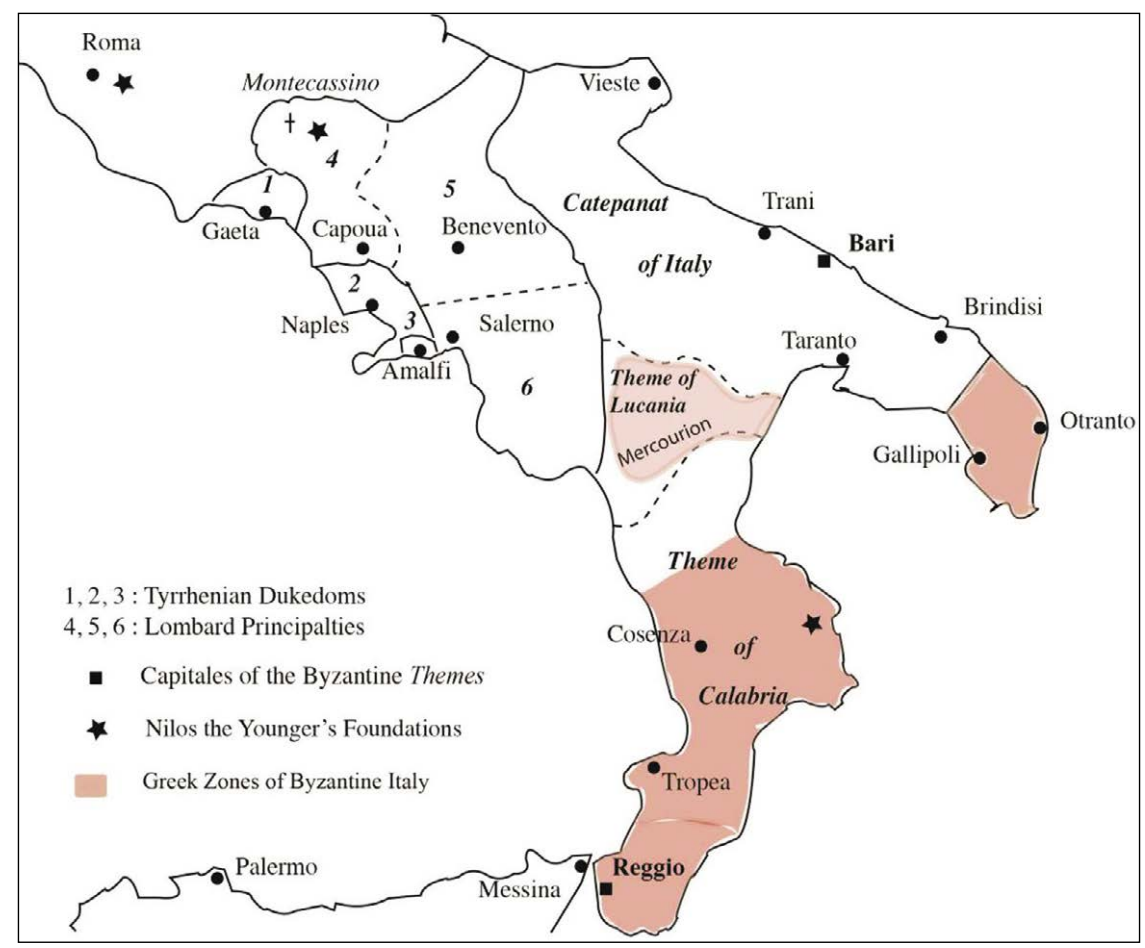

Fig. 1 - Carte politique générale de l'Italie méridionale continentale au début du $\mathrm{XI}^{\mathrm{e}}$ siècle (avant la conquête normande)

(Peters-Custot, 2017b) 


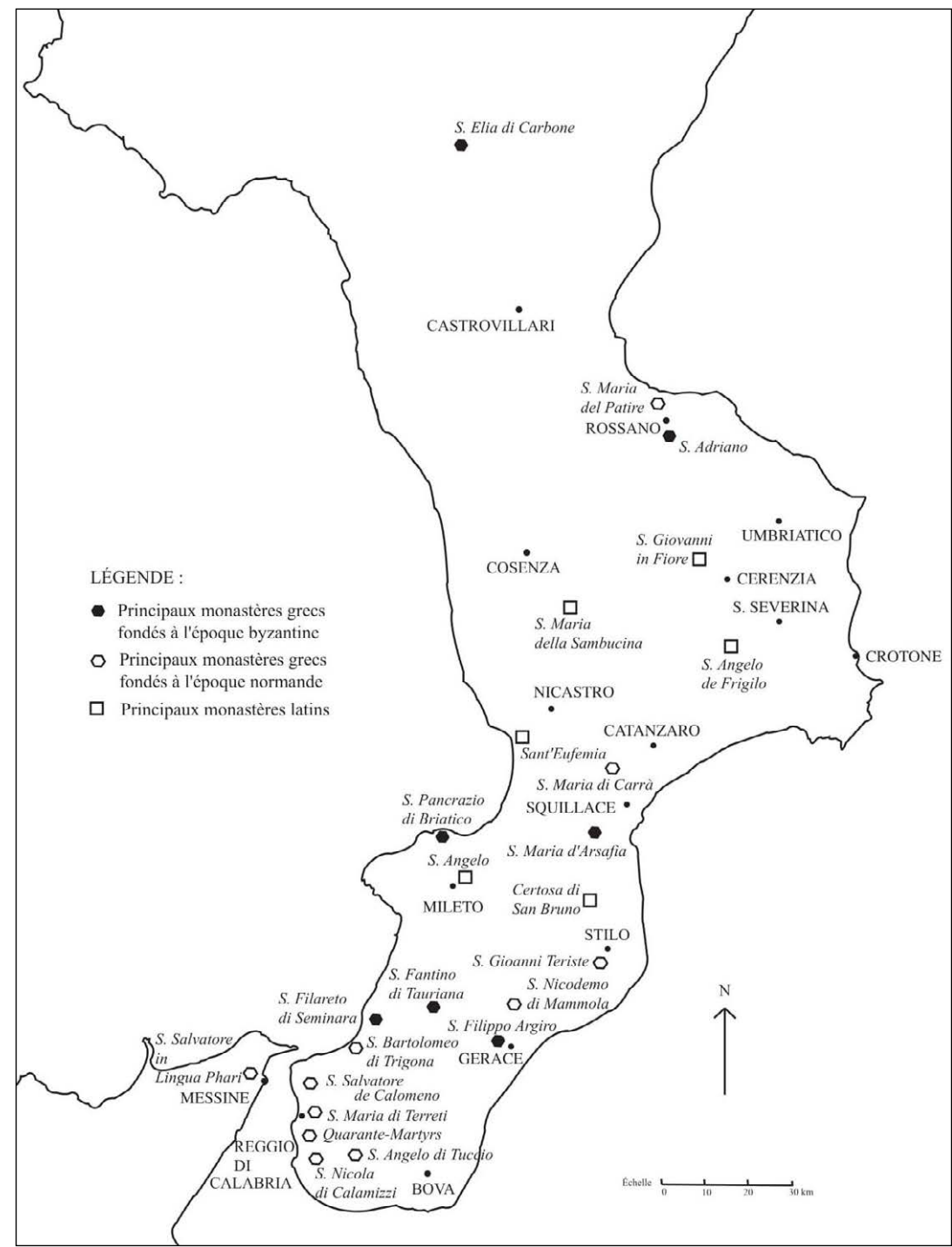

Fig. 2 - Carte monastique de la Calabre (IX ${ }^{\mathrm{e}}-\mathrm{XII}^{\mathrm{e}}$ siècles)

(Peters-Custot, 2009, p. 600) 


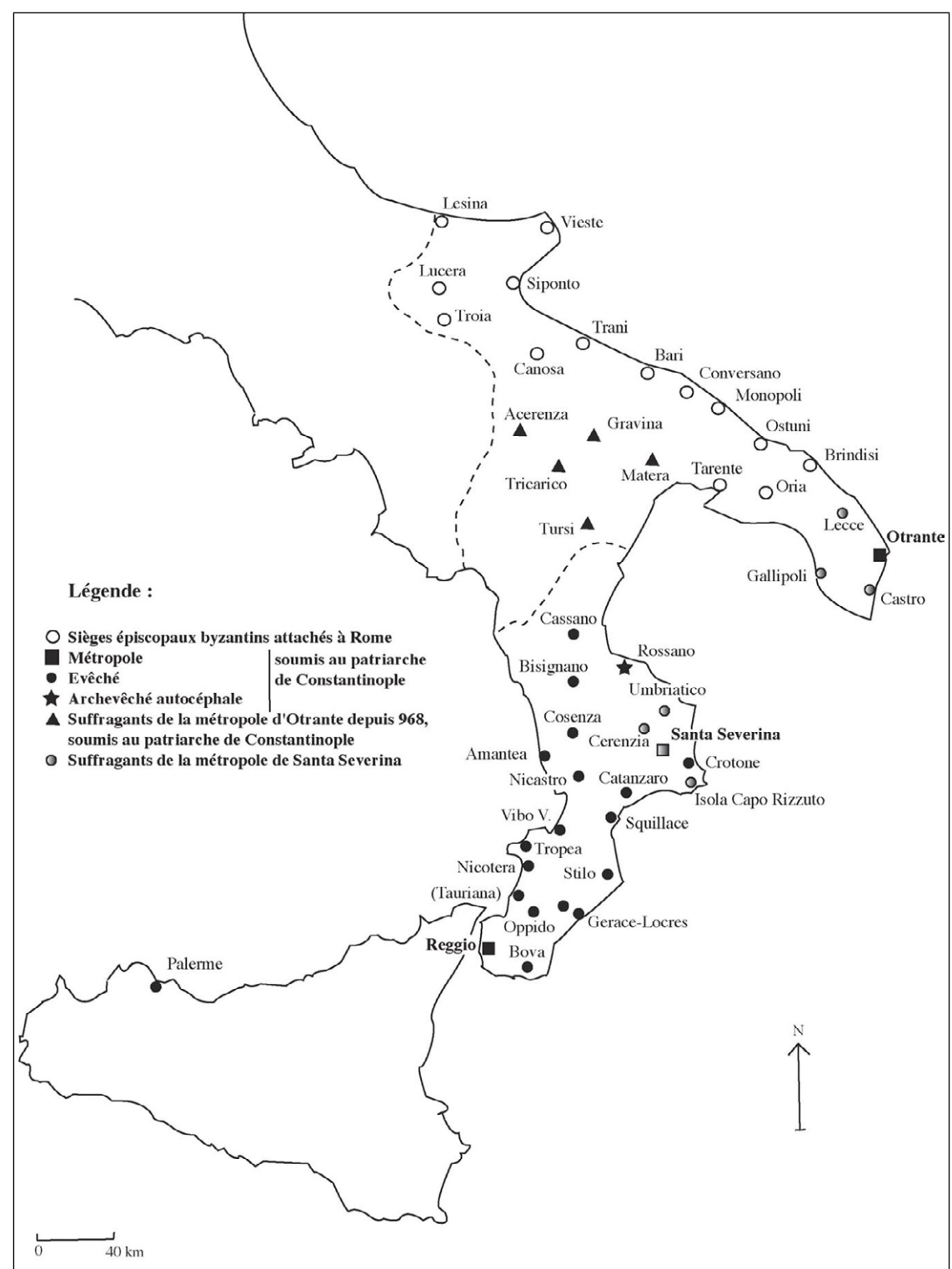

Fig. 3 - Les diocèses de l'Italie byzantine vers 1030-1050 (Peters-Custot, 2009, p. 598) 


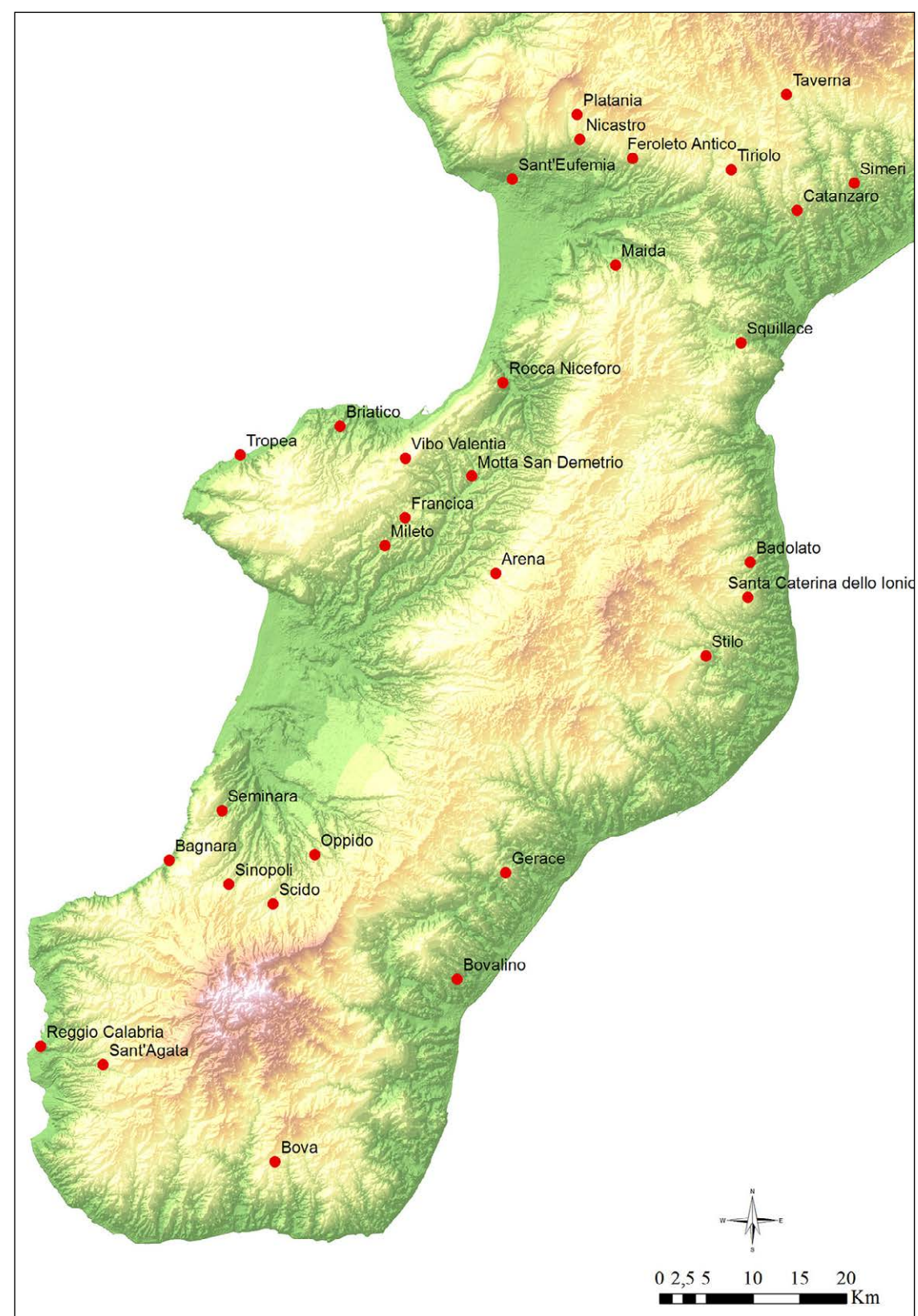

Fig. 4 - Villes les plus importantes de la Calabre centrale et méridionale (BERARDI, 2017a, annexe) 


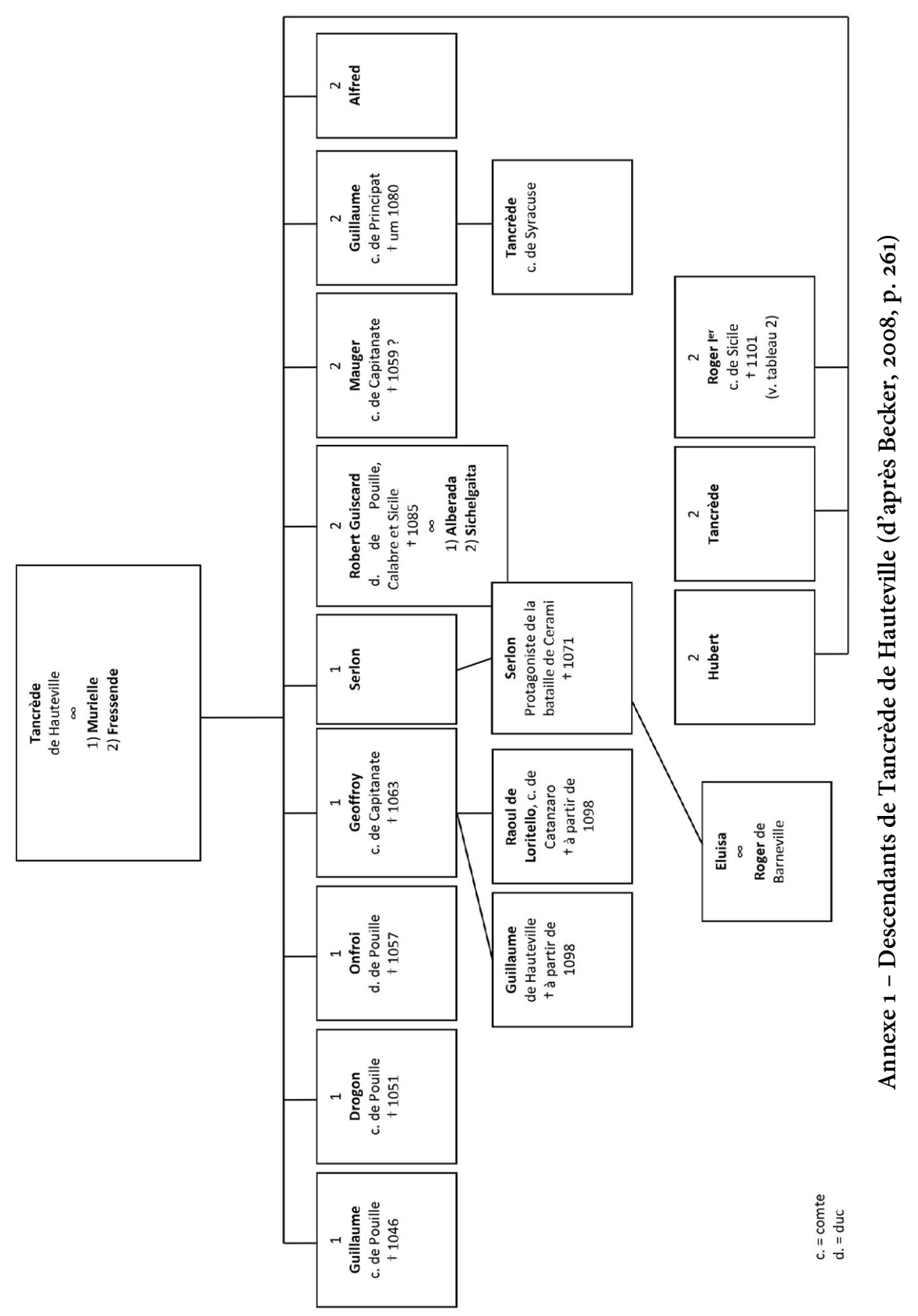




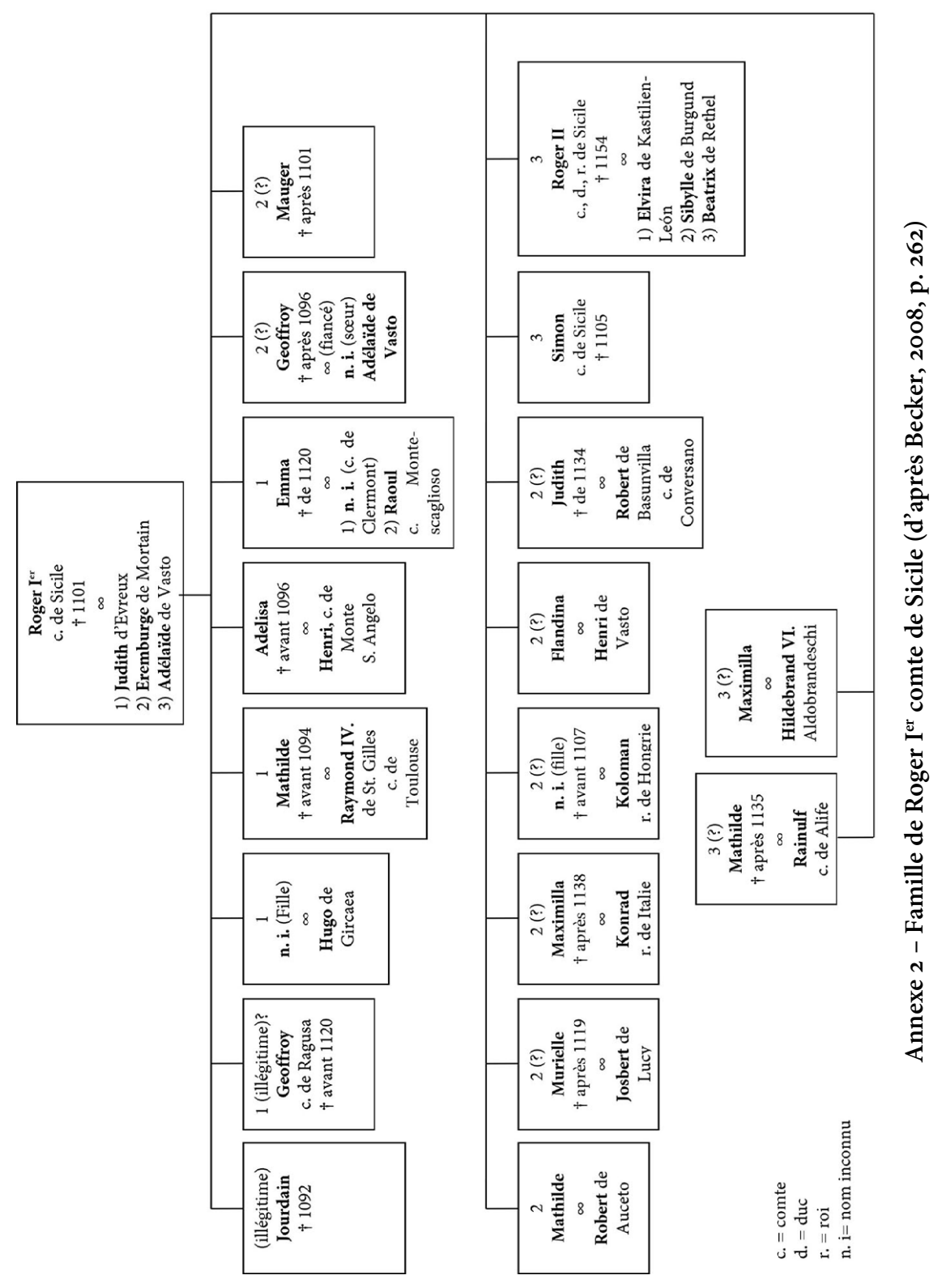




\section{Bibliographie}

\section{Sources}

\section{Sources inédites}

Archives du Collegio Greco di Roma, Fondo abbazia di Mileto.

Archives de Saint-Jean de Latran (Cité du Vatican), Fondo S. Maria di Bagnara.

Regia Camera della Sommaria, Dipendenze della Sommaria - II serie, Economi regi, 38/1 - Privilegi e istrumenti relativi alla mensa vescovile di Squillace.

Rome, Biblioteca Angelica, Giovanni Battista Prignano, Historia delle famiglie di Salerno normanne, ms. 276.

\section{Sources imprimées}

Acta Imperii inedita saeculi XIII et XIV: urkunden und Briefe zur Geschichte des Kaiserreichs und des Königreichs Sicilien in den Jahren 1198-140o, vol. I (1198-1273), E. Winkelmann (éd.), Innsbruck, Wagner, 188 o.

Actes de Docheiariou, N. Oıкоnomidès (éd.), Paris, P. Lethielleux (Archives de l'Athos, 13), 1984.

Actes d'Iviron, I. Des origines au milieu $d u$ XI $I^{e}$ siècle, J. Lefort, N. Oikonomidès et D. Papachryssanthou (éd.), avec la collaboration de H. Métrévéli, Paris, P. Lethielleux (Archives de l'Athos, 14), 1985.

Actes de Lavra, I. Première partie: des origines à 1204, P. Lemerle, A. Guillou, D. Papachryssanthou et N. Svoronos (éd.), Paris, P. Lethielleux (Archives de l'Athos, 5), 1970.

Actes du Prôtaton, D. Papachryssanthou (éd.), Paris, P. Lethielleux (Archives de l'Athos, 7), 1975.

Les actes grecs des fonds Aldobrandini et Miraglia (XI ${ }^{e}-X I I I^{e}$ s.), A. Guillou (éd.), Cité du Vatican, Biblioteca Apostolica Vaticana (Corpus des actes grecs d'Italie du Sud et de Sicile, 6), 2009.

Annibale De Leo, Codice diplomatico brindisino, I. (492-1299), G. M. Monti (éd.), Trani, Vecchi (Deputazione di storia patria per le Puglie, Sezione di Brindisi), 1940.

Le Assise di Ariano, testo critico, O. Zecchino (éd. et trad.), Cava dei Tirreni, Di Mauro, 1984.

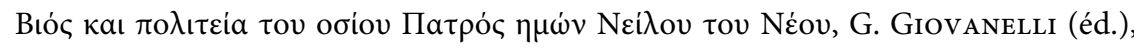
Grottaferrata, Badia di Grottaferrata, 1972.

Le brébion de la métropole byzantine de Règion (vers 1050), A. Guillou (éd.), Cité du Vatican, Biblioteca Apostolica Vaticana (Corpus des actes grecs d'Italie du Sud et de Sicile, 4), 1974.

Catalogus baronum, Rome, E. JAmison (éd.), Istituto Storico Italiano per il Medioevo (Fonti per la Storia d'Italia, 101), 1972.

Catalogus baronum. Commentario, E. Cuozzo (éd.), Rome, Istituto Storico Italiano per il Medioevo (Fonti per la Storia d'Italia, 101bis), 1984.

Decimae. Il sostegno economico dei sovrani alla Chiesa del Mezzogiorno nel XIII secolo: dai lasciti di Eduard Sthamer e Norbert Kamp, K. Toomaspoeg (éd.), Rome, Viella (Ricerche dell'Istituto Storico Germanico di Roma, 4), 2009. 
Documenti dell'Eremo della Torre e del monastero di Santo Stefano del Bosco (secc. XIXIII), F. IAntorno (éd.), Soveria Mannelli, Rubbettino (Codice Diplomatico della calabria, serie I, tome IV), 2010.

Documenti latini e greci del Conte Ruggero I di Calabria e Sicilia, J. BeCKer (éd.), Rome, Viella (Ricerche dell'Istituto Storico Germanico di Roma, 9), 2013.

I documenti inediti dell'epoca normanna in Sicilia. Parte prima, C. A. GARUfi (éd.), Palerme, Lo Statuto (Documenti per servire alla storia di Sicilia, Prima serie, Diplomatica, 18), 1899.

I Fascicoli della Cancelleria Angioina ricostruiti dagli Archivisti napoletani, vol. III, S. Palmieri (éd.), Naples, Arte Tipografica editrice (Testi e documenti di storia napoletana pubblicati dall'Accademia Pontaniana, serie III), 2008.

Gaufredo Malaterra, De rebus gestis Rogerii, Calabriae et Siciliae Comitis et Roberti Guiscardi Ducis fratris eius, auctore Gaufredo Malaterra monacho benedictino, E. Pontieri (éd.), Bologne, Nicola Zanichelli (Rerum italicarum scriptores, 5-1), 1928.

Geoffroi Malaterra, Histoire du Grand Comte Roger et de son frère Robert Guiscard, vol. I, livres I \& II, M.-A. Lucas-Avenel (éd. et trad.), Caen, Presses universitaires de Caen (Fontes \& Paginae), 2016.

Geoffroi Malaterra, Histoire du Grand Comte Roger et de son frère Robert Guiscard (Livres III \& IV), in M.-A. LuCAS-Avenel, Éditer des cuvres latines à l'ère du numérique: édition critique multisupport de Geoffroi Malaterra, Histoire du Grand Comte Roger et de son frère Robert Guiscard (Livres III \& IV), mémoire d'HDR, C. JACQUemard (garante), Université de Caen Normandie, 2019.

Guillaume de Pouille, La Geste de Robert Guiscard, M. MAthieu (éd. et trad.), Palerme, Istituto siciliano di studi bizantini e neoellenici (Testi e monumenti. Testi, 4), 1961.

KeHr, Karl Andreas, Die Urkunden der normannisch-sicilischen Könige : eine diplomatische Untersuchung, Innsbruck, Wagner, 1902.

KeHr, Paul Fridolin, Le Bolle Pontificie anteriori al 1198, che si conservano nell'Archivio di Montecassino, Montecassino, Tipografia di Montecassino (Miscellanea Cassinese, 2), 1899, p. 1-90; réimpr. dans KeHR, Paul Fridolin, Papasturkunden in Italien: reiseberichte zur Italia Pontificia, Cité du Vatican, Biblioteca Apostolica Vaticana (Acta Romanorum Pontificum, 1-6), 1977.

Le pergamene dell'archivio vescovile di Caiazzo (1007-1265), C. Salvati et al. (éd.), Caserte, Società di Storia Patria di Terra di Lavoro, 1983, 2 vol.

La Platea di Luca arcivescovo di Cosenza (1203-1227), E. Cuozzo (éd.), Avellino, Sellino editore (Medievalia, 8) 2008.

La Platea di S. Stefano del Bosco, P. De Leo (éd.), Soveria Mannelli, Rubbettino (Codice Diplomatico Calabrese, Serie I, tome I), 1998, vol. I-II.

Pseudo Ugo Falcando, De rebus circa Regni Siciliae curiam gestis; Epistola ad Petrum de desolatione Siciliae, E. D’Angelo (éd.), Rome - Florence, Istituto Storico Italiano per il Medioevo (Fonti per la storia dell'Italia medievale. Rerum italicarum Scriptores, 11) - Sismel (Edizione Nazionale dei Testi Mediolatini d'Italia, 36, Serie II, 16), 2014.

Radulphi Cadomensis, Tancredus, E. D’Angelo (éd.), Turnhout, Brepols (Corpus Christianorum Continuatio Mediaevalis, 231), 2011. 
Registrum Petri Diaconi (Montecassino, archivio dell'abbazia, reg. 3), J.-M. MARTIN et al. (éd.), Rome, École française de Rome (Sources et documents publiés par l'École française de Rome, 4) - Istituto Storico italiano per il Medioevo (Fonti per la storia dell'Italia medievale. Antiquitates, 45), 2015.

Saint-Jean-Théristès (1054-1264), S. G. Mercati, C. Giannelli et A. Guillou (éd.), Cité du Vatican, Biblioteca Apostolica Vaticana (Corpus des actes grecs d'Italie du Sud et de Sicile, 5), 1980.

Tancredi et Willelmi III regum diplomata, H. Zielinski (éd.), Cologne - Vienne, Böhlau (Codex diplomaticus Regni Siciliae. Series Prima, Diplomata regum et principum e gente Normannorum, 5), 1982.

La Théotokos de Hagia-Agathè (Oppido) (1050-1064/1065), A. Guillou (éd.), Cité du Vatican, Biblioteca Apostolica Vaticana (Corpus des actes grecs d'Italie du Sud et de Sicile, 3), 1972.

Syllabus graecarum membranarum..., F. Trinchera (éd.), Naples, J. Cataneo, 1865.

Ughelli, Ferdinando, Italia Sacra, vol. IX, Venise, Sebastianum Coleti, 1721.

\section{Études}

Albertoni, Giuseppe et Provero, Luigi, «Storiografia europea e feudalesimo italiano tra alto e basso medioevo", Quaderni Storici, 38, 2003, p. 243-268.

BAuduin, Pierre, La première Normandie ( $X^{e}-X I^{e}$ siècles): sur les frontières de la haute Normandie, identité et construction d'une principauté, Caen, Presses universitaires de Caen (Bibliothèque du Pôle universitaire normand), 2004.

BAuduin, Pierre, "Chefs normands et élites franques, fin $\mathrm{IX}^{\mathrm{e}}$-début $\mathrm{X}^{\mathrm{e}}$ siècle», in Les fondations scandinaves en Occident et les débuts du duché de Normandie, Actes du colloque de Cerisy-la-Salle (25-29 septembre 2002), P. BAuduin (dir.), Caen, Publications du Crahm, 2005, p. 181-194.

BAuduin, Pierre, "Les modèles anglo-normands en questions", in Nascita di un regno: poteri signorili, istituzioni feudali e strutture sociali nel Mezzogiorno normanno (1130-1194), Actes des dix-septièmes journées normandes-souabes (Bari, 10-13 octobre 2006), R. Licinio et F. Violante (éd.), Bari, Adda Editore (Università degli studi di Bari, Centro di studi normanno-svevi, Atti 17), 2008, p. 51-97.

Bauduin, Pierre, Le Monde franc et les Vikings (VIII ${ }^{e}-X^{e}$ siècle), Paris, Albin Michel (Bibliothèque de l'Évolution de l'humanité), 2009.

BAtes, David, The Normans and Empire: the Ford Lectures delivered in the University of Oxford during Hilary Term 2010, Oxford, Oxford University Press, 2013.

BeCKer, Julia, Graf Roger I. von Sizilien: Wegbereiter des normannischen Königreichs, Tübingen, Niemeyer (Bibliothek des Deutschen Historischen Instituts in Rom, 117), 2008a.

BECKER, Julia, «Un dominio tra due culture. La contea di Ruggero I alla fine dell’XI secolo», Quellen und Forschungen aus italienischen Archiven und Bibliotheken, 88, 2008b, p. 1-33.

Berardi, Riccardo, La contea di Corigliano: profilo storico, economico e sociale della Sibaritide (secoli XI-XVI), Rossano, Ferrari editore, 2015a. 
BERARDI, Riccardo, «Féodalité laïque et seigneurie ecclésiastique: le litige entre Ruffo, comte de Sinopoli, et les évêques de Mileto, autour des biens du monastère de S. Bartolomeo de Trigona (XIV e siècle)», Bullettin du Cercor, 39, 2015b, p. 89-115.

BERARDI, Riccardo, Feudalità laica e signoria ecclesiastica nel Mezzogiorno medievale: la Calabria dai normanni alla Guerra del Vespro (1040-1282) / Féodalité läque et seigneurie ecclésiastique en Italie du Sud au Moyen Âge: la Calabre des Normands à la guerre des Vêpres (1040-1282), Thèse de doctorat d'Histoire médiévale, Saint-Marino - Angers - Nantes, Università degli stuidi - École doctorale SCE Université Bretagne Loire/CRHIA, 2017a, 1 vol. (dactyl.).

BERARDI, Riccardo, "Terminology in the Models of Economic Structures in Medieval Calabria (11th-13th Centuries)», in Symbols and Models in the Mediterranean: Perceiving Through Cultures, Medworlds - Conférence internationale des mondes méditerranéens, Université de Calabre (9-11 septembre 2014), A. BARnes et M. Salerno (éd.), Newcastle upon Tyne, Cambridge Scholars Publishing, 2017b, p. 51-69.

Berardi, Riccardo, «Le platee o reintegre dei Sanseverino di Bisignano: diritti e prelievo signorile nella Calabria settentrionale (secc. XV-prima metà del XVI)», in La signoria rurale nell'Italia del tardo medioevo. Archivi e poteri feudali nel Mezzogiorno (XIV-XVI sec.), F. Senatore (éd.), Florence, Firenze University Press, (Reti Medievali E-Book), sous presse.

Bıвıcou, Hélène, «Une page d’histoire diplomatique de Byzance au XI ${ }^{\text {e }}$ siècle: Michel VII Doukas, Robert Guiscard et la pension des dignitaires ", Byzantion, 29-30, 1959-1960, p. 43-75.

Breccia, Gastone, "Archivum Basilianum. Pietro Menniti e il destino degli archivi monastici italo-greci», Quellen und Forschungen aus italienischen Archiven und Bibliotheken, 71, 1991, p. 14-105.

Breccia, Gastone, Nuovi contributi alla storia del Patir: documenti del Vat. gr. 2605, Rome, Comitato nazionale per le celebrazioni del millenario della fondazione dell'Abbazia di S. Nilo a Grottaferrata, 2005.

Bresc, Henri, «Le fief en Sicile: du don gratuit à la structuration de l'armée et de l'État", in Fiefs et féodalité dans l'Europe méridionale (Italie, France du Midi, Péninsule ibérique) $d u X^{e}$ au XIII siècle, Colloque international organisé par le Centre Européen d'art et civilisation médiévale de Conques et l'Université de Toulouse-Le Mirail (Conques, 6-8 juillet 1998), P. Bonnassie (dir.), Toulouse, CNRS, Université de Toulouse-Le Mirail UMR 5136 (Méridiennes), 2002, p. 75-91.

Brown, Elizabeth A.R., «Feudalism, the tyranny of a construct», American Historical Review, 79, 1974, p. 1063-1088.

CARocci, Sandro, "Signori e Signorie», in Storia d'Europa e del Mediterraneo. Dal Medioevo all'età della globalizzazione. Sezione IV: Il Medioevo (secoli V-XV), vol. VIII: Popoli, potere, dinamiche, S. CArocci et A. BArbero (dir.), Rome, Salerno Editrice, 2006, p. 409-448.

CARocci, Sandro, "Giustizia signorile e potere regio nel regno normanno", in Puer Apuliae: mélanges offerts à Jean-Marie Martin, E. Cuozzo, V. Déroche, A. Peters-Custot et V. Prigent (éd.), Paris, ACHCB (Centre de recherche d'histoire et civilisation de Byzance, Monographies, 30), 2008, p. 123-138. 
CARocci, Sandro, «Angararii e franci. Il villanaggio meridionale», in Studi in margine all'edizione della Platea di Luca arcivescovo di Cosenza (1203-1227), E. Cuozzo et J.-M. Martin (éd.), Avellino, Sellino editore (Medievalia, 8bis), 2009, p. 205-242.

CARoccI, Sandro, Signorie di Mezzogiorno. Società rurali, poteri aristocratici e monarchia (XII-XIII secolo), Rome, Viella (La Storia. Saggi, 6), 2014; traduit en anglais par L. Byatt, Carocci, Sandro, Lordships of Southern Italy: Rural Societies, Aristocratic Powers and Monarchy in the 12th and 13th Centuries, Rome, Viella (History, Art and Humanities Collection, 5), 2018.

CARoccI, Sandro et LorÉ, Vito, «Accedere alla comunità. Italia meridionale, XIXIII secolo", in Cittadinanze medievali: dinamiche di appartenenza a un corpo comunitario, S. Menzinger (dir.), Rome, Viella (I Libri di Viella, 268), 2017, p. 27-44.

Cheynet, Jean-Claude, "Fortune et puissance de l'aristocratie ( $\mathrm{X}^{\mathrm{e}}-\mathrm{XII}{ }^{\mathrm{e}}$ siècle) $)$, in Hommes et richesses dans l'Empire byzantin, $I I$ : VIII ${ }^{e} X V^{e}$ siècle, V. KravarI, J. Lefort et C. Morrison (dir.), Paris, Éditions P. Lethielleux (Réalités byzantines, 2), 1991, p. 199-213; réimpr. dans CHEYnET, Jean-Claude, The Byzantine Aristocracy and its Military Function, Aldershot, Ashgate (Variorum Collected Studies, 859), 2006.

Cheynet, Jean-Claude, «Les gestionnaires des biens impériaux: étude sociale ( $\mathrm{X}^{\mathrm{e}}$ XII ${ }^{e}$ siècles)», in Mélanges Cécile Morrisson, Paris, Collège de France - CNRS, Association des Amis du Centre d'histoire et civilisation de Byzance (Travaux et Mémoires, 16), 2010, p. 163-204.

Cuozzo, Errico, Quei maledetti Normanni: cavalieri e organizzazione militare nel Mezzogiorno normanno, Naples, Guida editori (L'altra Europa, 4), 1989.

Cuozzo, Errico, "Les évêques d'origine normande en Italie et en Sicile», in Les Évêques normands du XI $I^{e}$ siècle, Actes du Colloque de Cerisy-la-Salle (3o septembre3 octobre 1993), P. Bouet et F. Neveux (éd.), Caen, Presses universitaires de Caen, 1995a, p. 67-78.

Cuozzo, Errico, Normanni: nobiltà e cavalleria, Salerne, Gentile editore, 1995b.

Cuozzo, Errico, «Corona, contee e nobiltà feudale all'indomani dell'elezione di Tancredi", in Tancredi, conte di Lecce, re di Sicilia, Actes de la Conférence internationale (Lecce, 19-21 février 1998), H. Houben et B. Vetere (éd.), Galatina, Congedo (Saggi e Testi, 16), 2004, p. 99-116.

Cuozzo, Errico, «Le istituzioni politico-amministrative legate alla conquista. Le ripartizioni territoriali : i comitati», in I caratteri originari della conquista normanna. Diversità e identità nel Mezzogiorno (1030-1130), Actes des seizièmes journées normandes-souabes (Bari, 5-8 octobre 2004), R. Licinio et F. Violante (éd.), Bari, Dedalo (Università degli studi di Bari, Centro di studi normanno-svevi, Atti 16), 2006, p. 287-304.

Cuozzo, Errico, La cavalleria nel Regno normanno di Sicilia, Atripalda, Mephite, 2008 (réédition de 2002).

DéBAX, Hélène, La seigneurie collective. Pairs, pariers, paratge. Les coseigneurs du XI $I^{e}$ au XIII ${ }^{e}$ siècle, Rennes, Presses universitaires de Rennes (Histoire), 2012.

DecaËNs, Joseph, «Le patrimoine des Grentemesnil en Normandie, en Italie et en Angleterre aux $\mathrm{XI}^{\mathrm{e}}$ et $\mathrm{XII}^{\mathrm{e}}$ siècles », in Les Normands en Méditerranée dans le sillage des Tancrède, Actes du Colloque de Cerisy-la-Salle (24-27 septembre 1992), Caen, Presses universitaires de Caen, 1994, p. 123-140. 
Di Muro, Alessandro, «Liste di uomini e società rurali nella Campania normanna premonarchica (ca 1050-1130)», in Le radici profonde non gelano: Adriano e San Nicolò Politi, 1117-2017, M. BuA et M. LeOnARDi (éd.), Viagrande, Algra editore, 2018, p. 35-44.

DöLGER, Franz, Beiträge zur Geschichte der byzantinischen Finanzverwaltung besonders des 10. und 11. Jahrhunderts, Leipzig, B. G. Teubner, 1927 (Byzantinisches Archiv, 9), rééd. dans Darmstadt, Wissenschaftliche Buchgemeinschaft, 1960.

Falkenhausen, Vera von, «Zur Regentschaft der Gräfin Adelasia del Vasto in Kalabrien und Sizilien (1101-1112)", in Aetos: Studies in Honour of Cyril Mango Presented to him on April 14, 1998, I, I. ŠEvČEnKo et I. HutTer (éd.), Stuttgart-Leipzig, B. G. Teubner, 1998, p. 87-115.

Falkenhausen, Vera von, «S. Bartolomeo di Trigona: storia di un monastero greco nella Calabria normanno-sveva», Rivista di studi bizantini e neoellenici, 36, 1999, p. 93-116.

Falkenhausen, Vera von, «Maximilla regina, soror Rogerius rex», in Italia et Germania. Liber Amicorum Arnold Esch, H. Keller, W. Paravicini et W. Schieder (éd.), Tübingen, Niemeyer, 2001, p. 361-377.

Falkenhausen, Vera von, "I funzionari greci nel regno normanno", in ByzantinoSicula V: Giorgio di Antiochia. L'arte della politica in Sicilia nel XII secolo tra Bisanzio e l'Islam, Actes de la Conférence internationale (Palerme, 19-20 april 2007), M. Re et C. Rognoni (éd.), Palerme, Istituto siciliano di studi bizantini e neoellenici (Quaderni, 17), 2009, p. 165-202.

FALKenhausen, Vera von, «Amministrazione fiscale nell'Italia meridionale bizantina (secoli IX-XI)», in L'héritage byzantin en Italie (VIII ${ }^{e}$-XII ${ }^{e}$ siècle), II. Les cadres juridiques et sociaux et les institutions publiques, Actes des $2^{\mathrm{e}}$ et $3^{\mathrm{e}}$ Tables rondes tenues à Rome (4-5 mai 2009 et 26-27 février 2010), J.-M. Martin, A. PetersCustot et V. Prigent (éd.), Rome, École française de Rome (Collection de l'École française de Rome, 461), 2012, p. 533-556.

Falkenhausen, Vera von, «The Graeco-Byzantine Heritage in the Norman Kingdom of Sicily", in Norman Tradition and Transcultural Heritage: Exchange of Cultures in the "Norman" peripheries of Medieval Europe, S. BurkhardT et T. Förster (éd.), Farnham, Ashgate, 2013a, p. 57-78.

Falkenhausen, Vera von, "Ancora sul monastero greco di S. Nicola dei Drosi (Prov. Vibo Valentia). Edizione degli atti pubblici (secoli XI-XII)», Archivio Storico per la Calabria e la Lucania, 79, 2013b, p. 37-80.

FALKenhausen, Vera von, «Un processo calabrese (Tropea 1105). Ilarione categumeno di San Pancrazio di Briatico vs. Pietro Gatto», in Honos alit artes: studi per il settantesimo compleanno di Mario Ascheri. II. Gli universi particolari: città e territori dal medioevo all'étà moderna, P. MAFFeI et G. M. VARANini (éd.), Florence, Firenze University Press (Reti Medievali E-Book, 19/2), 2014, p. 475-484.

Falkenhausen, Vera von, "Testo e contesto: un "katonoma" inedito della contessa Adelasia per il monastero di Bagnara (settembre 1111)", in Ingenita curiositas: Studi sull'Italia medievale per Giovanni Vitolo, B. Figlivolo, R. Di Meglio et A. Ambrosio (éd.), vol. III, Battipaglia, Laveglia Carlone, 2018, p. 1273-1290.

FAlKenhausen, Vera von, «Le città calabresi dalla conquista normanna fino alla fondazione del Regno", in La conquista e l'insediamento dei Normanni e le città del Mezzogiorno italiano, Actes de la conférence Salerno-Amalfi (10-11 novembre 2017), Amalfi, Centro di Cultura e Storia Amalfitana (Atti, 16), 2019, p. 173-192. 


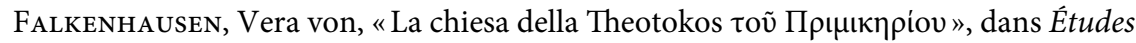
à la mémoire d'André Jacob (titre provisoire), à paraître.

Fernández-Aceves, Hervin, County and Nobility in Norman Italy. Aristocratic Agency in the Kingdom of Sicily, 1130-1189, London - New York, Bloomsbury Academic, 2020.

Feller, Laurent, «Le développement des institutions féodales dans les Abruzzes adriatiques et l'épiscopat de Raynulf de Chieti (1087-1105)», in Cavalieri alla conquista del Sud: studi sull'Italia normanna in memoria di Léon-Robert Ménager, E. Cuozzo et J.-M. Martin (éd.), Rome, Laterza (Collana di Fonti e Studi, 4) 1998, p. 194-215.

Fodale, Salvatore, Comes et legatus Siciliae: sul privilegio de Urbano II e la pretesa Apostolica Legazia dei Normanni di Sicilia, Palerme, U. Manfredi Editore (StudiUniversità di Palermo. Istituto di Storia medioevale, 2), 1970, rééd. FodAlE, Salvatore, L'Apostolica Legazia e altri studi su Stato e Chiesa, Messine, Sicania (Historica, 5), 1991.

Garufi, Carlo Alberto, «Gli Aleramici e i Normanni in Sicilia e nelle Puglie. Documenti e ricerche", in Centenario della nascita di Michele Amari. Scritti di filologia e storia araba, di geografia, storia, diritto della Sicilia medievale. Studi bizantini egiudaici relativi all'Italia meridionale nel medio evo. Documenti sulle relazioni fra gli stati italiani ed il levante, I, Palerme, Virzi, 1910, 2 vol., p. 47-83.

Garufi, Carlo Alberto, «Censimento e catasto della popolazione servile. Nuovi studi e ricerche sull'ordinamento amministrativo dei Normanni in Sicilia nei secoli XI e XII », Archivio Storico Siciliano, 49, 1928, p. 1-100.

Gillingham, John, The English in the Twelfth Century: Imperialism, National Identity and Political Values, Woodbridge, Boydell Press, 2000.

Green, Judith, Forging the Kingdom: Power in English Society, 973-1189, Cambridge, Cambridge University Press, 2017.

Guerreau, Alain, Le féodalisme: un horizon théorique, Paris, Le Sycomore, 1980.

Guillou, André et Holtzmann, Walter, «Zwei Katepansurkunden aus Tricarico», Quellen und Forschungen aus italienischen Archiven und Bibliotheken, 41, 1961, p. 1-28; réimpr. dans Guillou, André, Studies on Byzantine Italy, Londres, Variorum Reprints, 1970.

Hagger, Mark, Norman Rule in Normandy (911-1144), Woodbridge, Boydell Press, 2017.

Houben, Houbert, Ruggero II di Sicilia: un sovrano tra Oriente e Occidente, Rome Bari, Laterza (Collana di Fonti e Studi, 8), 1999.

Jamison, Evelyn Mary, "Additional Work on the Catalogus baronum», Bullettino dell'Istituto Storico Italiano per il Medioevo, 83, 1971, p. 1-63.

Lefort, Jacques, «The Rural Economy, Seventh-Twelfth Centuries», in The Economic History of Byzantium: From the Seventh through the Fifteenth Century, vol. I, A. E. Laiou (éd.), Washington, Dumbarton Oaks (Dumbarton Oaks Studies, 39), 2002, p. 231-310.

LEFORT, Jacques, «Le cadastre de Radolibos (1103), les géomètres et leurs mathématiques», Travaux et Mémoires du Centre de recherche d'histoire et civilisation de Byzance, 8 , 1981, p. 269-313; réimpr. dans LEFORT, Jacques, Société rurale et histoire du paysage à Byzance, Paris, Association des amis du Centre d'histoire et civilisation de Byzance (Bilans de recherche, 1), 2006, p. 105-154. 
Lefort, Jacques et Martin, Jean-Marie, «Le sigillion du catépan d'Italie Eustathe Palatinos pour le juge Byzantios (décembre 1045)», Mélanges de l'École française de Rome. Moyen Âge - Temps modernes, 98/2, 1986, p. 525-542, DOI: 10.3406/ mefr.1986.2874.

Leicht, Pier Silverio, "Gli excusati nelle province italiane soggette all'Impero d'Oriente», Papers of British School at Rome, 24, 1956, p. 22-28, DOI: 10.1017/ Soo68246200006760.

LoNGO, Umberto, «Il monachesimo benedettino come fattore di coesione territoriale e l'incontro di tradizioni e usi monastici al tempo della Riforma della Chiesa. Nuove ipotesi", in Oltre l'Alto Medioevo: etnie, vicende, culture nella Puglia normanno-sveva. Atti del XXII Congresso internazionale di studio sull'alto medioevo (Savelletri di Fasano-BR, 21-24 novembre 2019), Spoleto, Cisam (Atti dei Congressi, 22), 2020, p. 259-279.

LORÉ, Vito, «Beni principeschi e partecipazione al potere nel Mezzogiorno longobardo», in Italia, 888-962: una svolta, IV. Seminario Internazionale, Cassero di Poggio Imperiale a Poggibonsi (SI), (4-6 décembre 2009), M. VALenti et C. Wickham (éd.), Turnhout, Brepols (Seminari del Centro interuniversitario per la storia e l'archeologia dell'alto medioevo, IV), 2013, p. 15-40.

LoRÉ, Vito, «Curtis regia e beni dei duchi. Il patrimonio pubblico nel regno longobardo», in Biens publics, biens du roi: les bases économiques des pouvoirs royaux dans le haut Moyen Âge/Beni pubblici, beni del re: le basi economiche dei poteri regi nell'alto medioevo, V. Loré et F. Bougard (éd.), Turnhout, Brepols (Seminari del Centro interuniversitario per la storia e l'archeologia dell'alto medioevo, IX), 2019, p. 31-78.

Loud, Graham, The Age of Robert Guiscard: Southern Italy and the Norman Conquest, Essex-Harlow, Longman / Pearson Education (The Medieval World), 2000.

Loud, Graham, The Latin Church in Norman Italy, Cambridge, Cambridge University Press, 2007.

Loud, Graham (éd. et trad.), Roger II and the Making of the Kingdom of Sicily, Manchester - New York, Manchester University Press (Manchester Medieval Sources Series), 2012.

Loud, Graham, «Le strutture del potere: la feudalità », in Il Mezzogiorno normannosvevo fra storia e storiografia, Actes des vingtièmes journées normandes-souabes (Bari, 8-10 octobre 2012), P. Condasco et M. A. Siciliani (éd.), Bari, Adda Editore (Università degli studi di Bari, Centro di studi normanno-svevi, Atti 20), 2014, p. $147-167$.

Loud, Graham, «Labour Services and Peasant Obligations in Twelfth- and ThirteenthCentury Southern Italy», in Italy and Early Medieval Europe: papers for Chris Wickham, R. Balzaretti, J. Barrow et P. Skinner (éd.), Oxford, Oxford University Press (The Past \& Present Book Series), 2018, p. 182-199.

Loud, Graham, "Migration, Infiltration, Conquest and Identity: the Normans of Southern Italy c. 1000-1130", in Le migrazioni nell'Alto Medioevo (Spolète, 5-11 avril 2018), Spolète, Fondazione Centro italiano di studi sull'alto medioevo (Settimane di studio della Fondazione Centro italiano di studi sull'alto Medioevo, 66), 2019, p. 339-358.

KaPlan, Michel, Les hommes et la terre à Byzance du VIe au XIe siècle, Paris, Publications de la Sorbonne (Byzantina Sorbonensia, 10), 1992. 
Macchione, Antonio, «Da san Nilo all'affermazione del monachesimo latino in Calabria», Hortus Artium Medievalium, vol. 23-1, 2017, p. 337-345.

MARTin, Jean-Marie, «Le travail agricole: rythmes, corvées, outillage», in Terra e uomini nel Mezzogiorno normanno-svevo, Actes des septièmes journées normandes-souabes (Bari, 15-17 octobre 1985), G. Musca (éd.), Bari, Dedalo (Università degli studi di Bari, Centro di studi normanno-svevi, Atti 7), 1987, p. 113-157; réimpr. dans MARTIN, Jean-Marie, Byzance et l'Italie méridionale, Paris, Association des amis du Centre d'histoire et civilisation de Byzance (Bilans de recherche, 9), 2014, p. 251-284.

Martin, Jean-Marie, La Pouille du VI $I^{e}$ au XII siècle, Rome, École française de Rome (Collection de l'École française de Rome, 179), 1993.

Martin, Jean-Marie, "L'administration du Royaume entre Normands et Souabes", in Die Staufer im Süden: Sizilien und das Reich, T. KöLzER (éd.), Sigmaringen, J. Thorbecke, 1996, p. 113-140.

MARTIN, Jean-Marie, La vita quotidiana nell'Italia meridionale al tempo dei Normanni, M. G. Meriggi (trad.), Milan, Rizzoli, 1997, trad. italienne de Martin, JeanMarie, Italies Normandes ( $X^{e}-X I I^{e}$ siècles), Paris, Hachette (La Vie Quotidienne, Civilisations et sociétés), 1994.

Martin, Jean-Marie, «Pratiques successorales en Italie méridionale ( $\mathrm{X}^{\mathrm{e}}-\mathrm{XII}{ }^{\mathrm{e}}$ siècle): Romains, Grecs et Lombards", in La transmission du patrimoine: Byzance et l'aire méditerranéenne, Actes du colloque tenu à la Fondation Hugot du Collège de France (24-25 novembre 1995), J. Beaucamp et G. Dagron (éd.), Paris, De Boccard (Travaux et Mémoires du Centre de recherche d'histoire et civilisation de Byzance, Monographies, 11), 1998, p. 189-210.

MARTIN, Jean-Marie, "Aristocraties et seigneuries en Italie méridionale aux XI et XII e siècles: essai de typologie», Journal des savants, 1999, p. 227-259.

Martin, Jean-Marie, «Centri fortificati, potere feudale e organizzazione dello spazio», in Storia della Calabria medievale, vol. I, A. Placanica (éd.), Rome-Reggio Calabria, Gangemi editore, 2001, p. 485-522.

MARTIn, Jean-Marie, «Le droit lombard en Italie méridionale (IX ${ }^{\mathrm{e}}$-XIII ${ }^{\mathrm{e}}$ siècle) : interprétations locales et expansion ", in Dots et douaires dans le haut Moyen Âge, F. Bougard, L. Feller et R. Le Jan (éd.), Rome, École française de Rome (Collection de l'École française de Rome, 295), 2002, p. 97-121.

MARTIN, Jean-Marie, Guerre, accords et frontières en Italie méridionale pendant le haut Moyen Âge: Pacta de Liburia, Divisio principatus Beneventani et autres actes, Rome, École française de Rome (Sources et documents d'histoire du Moyen Âge, 7), 2005.

MARTIN, Jean-Marie, «Les thèmes italiens: territoire, population, administration», in Histoire et culture dans l'Italie byzantine: acquis et nouvelles recherches, actes de la table ronde réunie à Paris le 22 août 2001 dans le cadre du XX congrès international des Études byzantines, A. JАСОв, J.-M. MARTin et G. NoyÉ (éd.), Rome, École française de Rome (Collection de l'École française de Rome, 363), 2006, p. 517-558; réimpr. dans MARTIN, Jean-Marie, Byzance et l'Italie méridionale, Paris, Association des amis du Centre d'histoire et civilisation de Byzance (Bilans de recherche, 9), 2014, p. 197-229. 
MARTIN, Jean-Marie, «Fortifications isolées dans les campagnes de l'Italie méridionale», in Motte, torri e caseforti nelle campagne medievali (secoli XII-XV): omaggio ad Aldo A. Settia, Atti del Convegno svoltosi a Cherasco presso la sede del CISIM (23-25 septembre 2005), R. Сomba, F. Panero et G. Pinto (éd.), Cherasco, Centro Internazionale di Studi sugli insediamenti medievali, 2007, p. 343-354.

Martin, Jean-Marie, "Les seigneuries monastiques», in Nascita di un regno: poteri signorili, istituzioni feudali e strutture sociali nel Mezzogiorno normanno (1130-1194), Actes des dix-septièmes journées normandes-souabes (Bari, 10-13 octobre 2006), R. Licinio et F. Violante (éd.), Bari, Adda Editore (Università degli studi di Bari, Centro di studi normanno-svevi, Atti 17), 2008, p. 177-206.

MARtin, Jean-Marie, «Le platee calabresi», in Studi in margine all'edizione della Platea di Luca arcivescovo di Cosenza (1203-1227), E. Cuozzo et J.-M. Martin (éd.), Avellino, Sellino editore (Centro Europeo di Studi Normanni, Medievalia, 8bis), 2009, p. 113-122.

Martin, Jean-Marie, «De l'usage des dignités impériales en Italie (fin du VIII ${ }^{\text {-début }}$ du XII ${ }^{\mathrm{e}}$ siècle)», in Mélanges Cécile Morrisson, Paris, Collège de France - CNRS, Association des Amis du Centre d'histoire et civilisation de Byzance (Travaux et Mémoires, 16), 2010, p. 533-548.

MARTIN, Jean-Marie, «Le service public, critère de distinction des élites: Italie méridionale de tradition byzantine et lombarde ( $\mathrm{X}^{\mathrm{e}}$-XIII ${ }^{\mathrm{e}}$ siècle) », Mélanges de l'École française de Rome - Moyen Âge, 124-2, 2012, p. 531-545, DOI: 10.400o/mefrm.971.

MARtin, Jean-Marie, "Évêchés et monastères "grecs" en Italie méridionale au Moyen Âge (VII ${ }^{\mathrm{e}}$-XIII ${ }^{\mathrm{e}}$ siècle)", Revue Mabillon, 27, 2016, p. 5-22.

MÉNAgER, Léon-Robert, «Notes et documents sur quelques monastères de Calabre à l'époque normande», Byzantinische Zeitschrift, 50, 1957, p. 7-30 et p. 321-361.

MéNAger, Léon-Robert, «L'abbaye bénédictine de la Trinité de Mileto en Calabre à l'époque normande», Bollettino dell'Archivio paleografico italiano. Rivista italiana di paleografia, diplomatica e scienze ausiliarie della storia, 4-5, 1958-1959, p. 9-94.

MÉNAGER, Léon-Robert, «Addition à l'Inventaire des familles normandes et franques émigrées en Italie méridionale et en Sicile (XI ${ }^{\mathrm{e}}-\mathrm{XII}^{\mathrm{e}}$ siècles)», in MÉNAGER, Léon-Robert, Hommes et institutions de l'Italie normande: Essays by LéonRobert Ménager, Londres, Variorum Reprints (Collected Studies, 136), 1981, Essay V: 1-12.

MénAger, Léon-Robert, «Pesanteur et étiologie de la colonisation normande de l'Italie», in Roberto il Guiscardo e il suo tempo, Actes de colloque, Centro di studi normanno-svevi, università degli studi di Bari, 28-29 mai 1973 ( $1^{\text {re }}$ éd. 1975; réimpr. in Ménager L.-R., Hommes et institutions de l'Italie normande, Londres, Variorum Reprints, 1981), Bari, 1991, Dedalo editore, p. 203-229.

MÉNAGER, Léon-Robert, "Inventaire des familles normandes et franques émigrées en Italie méridionale et en Sicile (XI ${ }^{\mathrm{e}}-\mathrm{XII}{ }^{\mathrm{e}}$ siècles) », in Roberto il Guiscardo e il suo tempo, Actes de colloque, Centro di studi normanno-svevi, università degli

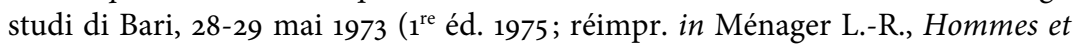
institutions de l'Italie normande, Londres, Variorum Reprints, 1981), Bari, 1991, Dedalo editore, p. 279-410.

Metcalfe, Alex, The Muslims of Medieval Italy, Édimbourg, Edinburgh University Press (The New Edinburgh Islamic Surveys), 2009. 
Moulet, Benjamin, Évêques, pouvoir et société à Byzance (VIII ${ }^{e}-X I^{e}$ siècle): territoires, communautés et individus dans la société provinciale byzantine, Paris, Publications de la Sorbonne (Byzantina Sorbonensia, 25), 2011.

Mineo, Ennio Igor, Nobiltà di stato: famiglie e identità aristocratiche del tardo medioevo. La Sicilia, Rome, Donzelli (Saggi, Storia e scienze sociali), 2001.

Nef, Annliese, «Conquêtes et reconquêtes médiévales: la Sicile normande est-elle une réduction en servitude généralisée? (Al-Andalus, Sicile et Orient latin) », Mélanges de l'École française de Rome - Moyen Âge, 112-2, dossier thématique «Les formes de la servitude: esclavages et servages de la fin de l'Antiquité au monde moderne», Actes de la table ronde de Nanterre (12-13 décembre 1997), 2000, p. 579-607, URL: www.persee.fr/doc/mefr_1123-9883_200o_num_112_2_9059.

Nef, Annliese, «La fiscalité en Sicile sous la domination islamique», in La Sicile de Byzance à l'Islam, A. Nef et V. Prigent (éd.), Paris, De Boccard (De l'archéologie à l'histoire), 2010, p. 131-156.

Nef, Annliese, Conquérir et gouverner la Sicile islamique aux XI et XII siècles, Rome, École française de Rome (Bibliothèque des Écoles françaises d'Athènes et de Rome, 346), 2011.

Molyneaux, George, The Formation of the English Kingdom in the Tenth Century, Oxford, Oxford University Press, 2015.

OıколоміDÈs, Nicolas, Les listes de préséance byzantines des $I X^{e}$ et $X^{e}$ siècles, Paris, Éditions du CNRS, 1972.

Oıкоnomidès, Nicolas, Fiscalité et exemption fiscale à Byzance (IX ${ }^{e}-X I^{e}$ s.), Athènes, Fondation nationale de la recherche scientifique, Institut de recherches byzantines (Monographies, 2), 1996.

Oıкonomidès, Nicolas, "The Role of the Byzantine State in the Economy", in The Economic History of Byzantium: from the Seventh through the Fifteenth Century, vol. III, A. E. LAiou (éd.), Washington, Dumbarton Oaks (Dumbarton Oaks Studies, 39), 2002, p. 973-1058.

PanArelli, Francesco, «Aspetti della molteplicità etnica nel monachesimo del Mezzogiorno normanno", Quellen und Forschungen aus italienischen Archiven und Bibliotheken, 85, 2005, p. 74-103, URL: https://prae.perspectivia.net/publikationen/ qfiab/85-2005/0074-0103.

PANARelli, Francesco, «Le istituzioni ecclesiastiche legate alla conquista. I monasteri», in I caratteri originari della conquista normanna. Diversità e identità nel Mezzogiorno (1030-1130), Atti delle sedicesime Giornate normanno-sveve (Bari, 5-8 ottobre 2004), R. Licinio e F. Violante (éd.), Bari, Dedalo, 2006, (Università degli studi di Bari, Centro di studi normanno-svevi, Atti 16), p. 349-369.

Panarelli, Francesco, "Matteo d'Aiello», in Dizionario Biografico degli Italiani, vol. 72, Rome, Istituto dell'Enciclopedia Italiana, 2008, p. 212-216, URL: https:// www.treccani.it/enciclopedia/matteo-d-aiello_\%28Dizionario-Biografico\%29/.

PanARELli, Francesco, «Citta, vescovi e Normanni», in La conquista e l'insediamento dei Normanni e le città del Mezzogiorno italiano, Actes de la conférence SalernoAmalfi (10-11 novembre 2017), Amalfi, Centro di Cultura e Storia Amalfitana (Atti, 16), 2019, p. 193-206.

Patlagean, Évelyne, Un Moyen Âge grec: Byzance $I X^{e}-X V^{e}$ siècle, Paris, Albin Michel (L'Évolution de l'humanité), 2007. 
Patlagean, Évelyne, "Les "hommes" (anthrôpoi) dans les documents grecs du Mezzogiorno normand», in Puer Apuliae: mélanges offerts à Jean-Marie Martin, E. Cuozzo, V. Déroche, A. Peters-Custot et V. Prigent (éd.), Paris, ACHCB (Centre de recherche d'histoire et civilisation de Byzance, Monographies, 30), 2008, p. 529-536.

Peters-Custot, Annick, «Brébion, kodex et plateae: petite enquête sur les instruments de la propriété monastique dans la Calabre méridionale aux époques byzantine et normande», in Puer Apuliae: mélanges offerts à Jean-Marie Martin, E. Cuozzo, V. Déroche, A. Peters-Custot et V. Prigent (éd.), Paris, ACHCB (Centre de recherche d'histoire et civilisation de Byzance, Monographies, 30), 2008, p. 537-552.

Peters-Custot, Annick, Les Grecs de l'Italie méridionale post-byzantine (IXe-XIVe siècle): une acculturation en douceur, Rome, École française de Rome (Collection de l'École française de Rome, 420), 2009a.

Peters-Custot, Annick, "Gli elenchi di uomini», in Studi in margine all'edizione della Platea di Luca arcivescovo di Cosenza (1203-1227), E. Cuozzo et J.-M. MArTin (éd.), Avellino, Sellino editore (Medievalia, 8bis), 2009b, p. 141-158.

Peters-Custot, Annick, «Comportement social et comportement culturel des élites rurales calabro-grecques d'après les actes de la pratique (XI'-XIII ${ }^{e}$ siècles) », L. FELLER, M. Kaplan, C. Picard (éd.), Mélanges de l'École française de Rome-Moyen Âge, 124-2, numéro thématique "Élites rurales méditerranéennes $\left(\mathrm{V}^{\mathrm{e}}-\mathrm{XV} \mathrm{V}^{\mathrm{e}}\right.$ siècles)», 2012a, p. 359-374, DOI: $10.4000 /$ mefrm.818.

Peters-Custot, Annick, «Titulatures byzantines en Pouille et Calabre», L'héritage byzantin en Italie (VIII ${ }^{e}-X I I^{e}$ siècle), II. Les cadres juridiques et sociaux et les institutions publiques, Actes des $2^{\mathrm{e}}$ et $3^{\mathrm{e}}$ Tables rondes tenues à Rome (4-5 mai 2009 et 26-27 février 2010), J.-M. Martin, A. Peters-Custot et V. Prigent (éd.), Rome, École française de Rome (Collection de l'École française de Rome, 461), 2012b, p. 643-658.

Peters-Custot, Annick, «La politique royale normande et les comtés calabrais dans la seconde moitié du XII ${ }^{\mathrm{e}}$ siècle: l'apport du fonds de S. Stefano del Bosco ", Mélanges de l'École française de Rome - Moyen Âge, 124-1, numéro thématique «Espaces monastiques et espaces urbains de l'Antiquité tardive à la fin du Moyen Âge", 2012C, DOI: 10.400o/mefrm.165.

Peters-Custot, Annick, Bruno en Calabre. Histoire d'une fondation monastique dans l'Italie normande: S. Maria de Turri et S. Stefano del Bosco, Rome, École française de Rome (Collection de l'École française de Rome, 489), 2014.

Peters-Custot, Annick, «Les plateae calabraises d'époque normande: une source pour l'histoire économique et sociale de la Calabre byzantine?", in L'Italia bizantina: una prospettiva economica, S. Cosentino (dir.), Paris, Classiques Garnier (Cahiers de recherches médiévales et humanistes, 28), 2015, p. 389-408.

Peters-Custot, Annick, «Plateae et anthrôpoi, peut-on trouver des origines byzantines à l'organisation normande de la paysannerie de la Calabre méridionale? ", in L'héritage byzantin en Italie, IV. Structures agraires et habitat rural, acte de la table ronde tenue à Rome (17-18 décembre 2010), J.-M. Martin, A. Peters-Custot et V. Prigent (dir.), Rome, École française de Rome (Collection de l'École française de Rome, 531), 2017a, p. 293-318. 
Peters-Custot, Annick, «Bessarion et le monachisme italo-grec: l'Orient en Italie du Sud?», Cahiers d'études italiennes, 25, 2017b, DOI: 10.400o/cei.3616.

Peters-Custot, Annick, «The Documentary Multilingualism and the Social Status of Effective Multilingualism in the Norman Southern Italy, 11th-12th Centuries", in Multilingual and Multigraphic Documents and Manuscripts of East and West, G. Mandalà et I. Pérez Martín (dir.), Piscataway, Gorgias Press (Perspectives on Linguistics and Ancient Languages, 5), 2018a, p. 293-313.

Peters-Custot, Annick, «Il monachesimo italo-greco nel periodo normanno-svevo e la sua evoluzione: ritorno su un processo da (ri)definire», in Civiltà a contatto nel Mezzogiorno normanno svevo. Economia, società, istituzioni. Atti delle ventunesime giornate normanno-svevo (Melfi, 13-14 ottobre 2014), M. Boccuzzi et P. CorDAsco (éd.), Bari, Adda Editore (Università degli studi di Bari, Centro di studi normannosvevi, Atti 21), 2018b, p. 219-239.

Petralia, Giuseppe, «La "signoria" nella Sicilia normanna e sveva: verso nuovi scenari? ", in La signoria rurale in Italia nel medioevo, Actes du deuxième congrès d'études (Pise, 6-7 novembre 1998), C. Violante et M. L. Ceccarelli Lemut (dir.), Pise, Edizioni ETS (Studi medioevali, 11), 2006, p. 233-272.

Prestwich, John, «War and finance in the Anglo-Norman state», Transactions of the Royal Historical Society, Series V.4, 1954, p. 19-43.

Reynolds, Susan, Fiefs and Vassals: The Medieval Evidence Reinterpreted, Oxford, Oxford University Press, 1994.

Rohlfs, Gerhard, Dizionario toponomastico e onomastico della Calabria, Ravenne, Longo Editore, 1974.

Rotman, Youval, «Formes de la non-liberté dans la campagne byzantine aux VII ${ }^{\mathrm{e}}$ $\mathrm{XI}^{\mathrm{e}}$ siècles", Mélanges de l'École française de Rome - Moyen Âge, 112-2, numéro thématique «Les formes de la servitude: esclavages et servages de la fin de l'Antiquité au monde moderne", Actes de la table ronde de Nanterre (12-13 décembre 1997), 2000, p. 499-510, URL: www.persee.fr/doc/mefr_1123-9883_2000_num_112_2_9054.

Russo, Luigi, «Tancredi e i bizantini. Sui Gesta Tancredi in expeditione Hierosolymitana di Rodolfo di Caen", Medioevo Greco. Rivista di storia e filologia bizantina, 2, 2002, p. 193-230.

SALERNo, Mariarosaria, Istituzioni religiose in Calabria in età medievale: note di storia economica e sociale, Soveria Mannelli, Rubbettino, 2006.

SAlERno, Mariarosaria, "Oriente e Occidente nel Mediterraneo: ripensare Antiochia Medievale (XI-XIII secc.)», in Continuité et rupture des échanges en Méditerranée: histoire, religion, littérature, société, J.-E. BERNARD et al. (dir.), Toulon, Université de Toulon (Transverses), 2016, p. 55-75.

SALERno, Mariarosaria, «S. Stefano del Bosco», in La signoria rurale nell'Italia del tardo medioevo. Censimento e quadri regionali, F. Del Tredici (éd.), S. CARocci (dir.), Rome, Editalia, sous presse.

SCHNeIder, Fedor, «Mittelgriechische Urkunden für San Filippo di Gerace», Quellen und Forschungen aus italienischen Archiven und Bibliotheken, 10, 1907, p. 247-274.

SenAtore, Francesco, «Parlamento e luogotenenza generale. Il regno di Napoli nella Corona d'Aragona", in La Corona de Aragón en el centro de su Historia (12081458): la Monarquía aragonesa y los reinos de la Corona, J. Á. Sesma Muñóz (éd.), Saragosse, Grupo de excelencia de investigación, CEMA-Universidad de Zaragoza (Colleción Garba, 4), 2010, p. 435-478. 
Senatore, Francesco, "Signorie personali nel Mezzogiorno (XIV-XVI sec.) », in $\mathrm{La}$ signoria rurale nell'Italia del tardo medioevo. Azione politica locale nelle campagne dell'Italia tardomedievale, A. Fiore, L. Provero (éd.), Florence, Firenze University Press (Reti Medievali E-Book), sous presse.

Siragusa, Giovanni, Il Regno di Guglielmo I in Sicilia. Illustrato con nuovi documenti, Palerme, Tipografia dello Statuto, 1885.

Stiernon, Daniel, «Basile de Reggio, le dernier métropolite grec de Calabre», Rivista di Storia Della Chiesa in Italia, 18, 1964, p. 189-226.

Skinner, Patricia, "When was Southern Italy "feudal" ?", in Il feudalesimo nell'alto medioevo, Semaines d'étude du Centre italien d'études sur le haut Moyen Âge, XLVII, (Spolète, 8-12 avril 1999), Spolète, Centro italiano di studi sull'alto medioevo, 2000, p. 309-340.

Svoronos, Nicolas, «Recherches sur le cadastre byzantin et la fiscalité aux XI et XII ${ }^{\mathrm{e}}$ siècles: le cadastre de Thèbes », Bulletin de correspondance hellénique, 83, 1959, p. 1-145, DOI : 10.3406/bch.1959.2318; réimpr. dans Svoronos, Nicolas, Études sur l'organisation intérieure, la société et l'économie de l'Empire byzantin, Londres, Variorum Reprints, 1973, III, p. 1-166.

VAranini, Gian Maria (éd.), «Signorie del Mezzogiorno d'Italia. Sguardi incrociati», Reti Medievali Rivista, 19-1, 2018, DOI: 10.6092/1593-2214/5612.

Wiскнам, Chris, «Le forme del feudalesimo», in Il feudalesimo nell'alto medioevo, Semaines d'étude du Centre italien d'études sur le haut Moyen Âge, XLVII, (Spolète, 8-12 avril 1999), Spolète, Centro italiano di studi sull'alto medioevo, 200o, p. 15-46. 